\title{
Global environmental impacts: data sources and methodological choices for calculating normalization factors for LCA
}

\author{
Eleonora Crenna ${ }^{1} \cdot$ Michela Secchi $^{1} \cdot$ Lorenzo Benini $^{1,2} \cdot$ Serenella Sala ${ }^{1}$
}

Received: 2 February 2018 / Accepted: 5 September 2018 / Published online: 25 March 2019

(C) The Author(s) 2019

\begin{abstract}
Purpose Characterizing environmental impacts at the global scale is crucial to define references against which compare the environmental profile of products and systems. Within this study, global emissions and resource uses have been collected and characterized for the following impact categories: climate change, ozone depletion, human toxicity (cancer and non-cancer), ecotoxicity, particulate matter, ionizing radiation, photochemical ozone formation, acidification, eutrophication (terrestrial, marine, and freshwater), land use, water use, and resource use. The results can be used as normalization factors (NFs) in the context of the life cycle assessment (LCA). Material and methods The global NFs are built on an extensive collection of data on emissions and resources extracted at a global scale in 2010, gathering different sources and comparing them. A hierarchical approach was applied to the selection of data sources. Extrapolations, mainly temporal data-gap filling, were applied for complementing the inventories for missing data. In order to calculate NFs, the inventory was characterized by using the International Reference Life Cycle Data System (ILCD) midpoint indicators and the EU Environmental Footprint (EF) set, which includes recently released models.

Results and discussion The resulting global NFs (ILCD and EF) were reported and discussed for each impact category. Coverage completeness and robustness of both the underpinning inventories and impact assessment models were used to define the level of uncertainty in the calculations. Based on the contribution analysis of the main elementary flows, it resulted that only few elementary flows drive the overall impact for most of the impact categories. Moreover, the ratio between the NFs at EU27 in 2010 and global level showed that Europe generally covers less than $10 \%$ of the global impact.

Conclusion and outlook The quantification of the current levels of environmental pressures entails critical aspects, as it consists of accounting of emissions and resources, relying on data often incomplete or based on modeling. Despite the attempts made for increasing NFs coverage and robustness, the calculation in the present study highlights the need of further efforts aiming at overcoming the uncertainties and the limitations identified both at the inventory (i.e., difficulty in retrieving complete and recent data) and characterization levels (e.g., consistency between inventory and impact assessment regarding spatialization, system boundaries). Most importantly, any assessment based on the use of NFs should be carefully discussed and interpreted in light of the limitations discussed in this paper.
\end{abstract}

Keywords Normalization factors · ILCD · Environmental footprint · Emissions $\cdot$ Life cycle impact assessment $\cdot$ Global inventory

\section{Introduction}

The growth of human population and the increase in consumption intensity at the global level have led to an

Responsible editor: Jeroen Guinée

Electronic supplementary material The online version of this article (https://doi.org/10.1007/s11367-019-01604-y) contains supplementary material, which is available to authorized users.

Serenella Sala

serenella.sala@ec.europa.eu

European Commission, Joint Research Centre, Ispra, VA, Italy

2 European Environment Agency, Copenhagen, Denmark unprecedented demand for natural resources needed in various sectors (e.g., food, energy, transport, materials, and chemicals production). This implies increasing pressures on the environment due to emissions of polluting substances and the consumption of resources. The assessment of the potential environmental impacts associated with those pressures and of the underpinning causes is a precondition for the identification and prioritization of possible solutions in terms of impact reduction and improved environmental performance.

Life cycle assessment (LCA) is a reference methodology for the evaluation of environmental impacts along the supply chain. Life cycle-based methodology is increasingly adopted to assess production and consumption patterns and to identify hotspots of impact which may represent the key areas of 
interventions where environmental pressures can be reduced. Through the so-called normalization step, impacts related to a specific product or system are compared with reference values describing the impacts associated with a reference system (e.g., another product, a region, a country, or the entire globe). In the LCA context and according to ISO 14044 (ISO 2006), normalization is an optional step that allows the interpretation of the characterized results in terms of relative environmental relevance of the impacts. In fact, normalization provides a reference situation for the environmental pressures of all the impact categories, meaning that - through normalizationabsolute impact scores are converted into relative contributions of the analyzed product or system to a reference situation (Sleeswijk et al. 2008). Normalization factors (NFs) are often composed of regional and global inventories of emissions and resource use, coupled with estimations of missing elementary flows (e.g., proxy for chemical emissions leading to impacts on toxicity, Cucurachi et al. 2014), and characterized by using an impact assessment method and the related models.

In 2016, the UNEP/SETAC Life Cycle Initiative has been discussing the role of normalization (Pizzol et al. 2017), recommending the use of global NFs since they are perceived as more relevant for decision-making, supporting the interpretation of the meaning of life cycle impact assessment (LCIA) results. In fact, normalization can play an important role in providing information on the magnitude of impacts, by comparing them with a reference state, thus facilitating the communication to stakeholders as well as supporting decision-making.

Over time, several normalization factors have been proposed at different levels, e.g., Sleeswijk et al. (2008) for Europe and global scale, Laurent et al. (2013) for the global scale, and Sala et al. (2015) for Europe. Important key limitations have been identified in previous studies (Benini and Sala 2016; Cucurachi et al. 2017; Prado et al. 2017; Heijungs et al. 2007), especially related to high uncertainty due to data gaps and the use of different sources or methodological approaches (as extensively highlighted in Benini and Sala 2016). However, possible alternatives are still not reported in the existing literature.

The present study has two goals: (i) develop an update inventory at global scale for the year 2010, exploring different available sources for building the inventory and showing the discrepancies/differences and (ii) make available set of normalization factors to be used with International Reference Life Cycle Data system (ILCD) (EC-JRC 2011) and Environmental Footprint (EF) (EC 2013a, b) methods.

Normalization factors are the result of an effort in building an inventory of emissions and resource use, describing also strengths, limitations, and possible uncertainties associated to the factors when using different sources for the inventory and different methodological choices in the characterization stage. Compared to previous studies underpinning normalization, this paper is built on a systematic review of different sources available for building the inventory, thus highlighting the potential uncertainties associated to the figures and offering potential options for sensitivity assessment. Moreover, building this inventory is fundamental to progress in the assessment of the potential impact due to current production and consumption patterns compared to planetary boundaries, which requires identifying global references of pressures and impacts (Sala et al. 2016).

The paper is organized as follows: "Section 2" presents the applied methodology, the data sources, and the assumptions made for building the inventories; "Section 3" reports the resulting normalization factors calculated for each impact category, including a discussion on the choices underpinning their estimations as well as their comparison with the EU27 NFs as calculated in Sala et al. (2015) and previously published global sets (Sleeswijk et al. 2008; Laurent et al. 2013); finally, in "Section 4," an outlook towards future improvements is presented. Supplementary Materials (ESM) are available and include the inventory database, alternative inventory data found in literature, the modeling choices, and the characterized inventory for each impact category.

\section{Methodology}

The environmental pressures associated to emissions into air, soil, and water and to resource extraction are traditionally estimated by adopting a territorial perspective, namely collecting statistical information associated with emissions and resource use occurring within a defined spatial scale. In the present study, the calculation of the global NFs was built on a collection of data from different sources on emissions and resources used at global scale, selecting 2010 as the reference year.

The inventories cover both emissions into the environmental compartments (i.e., air, water, and soil) and resources extracted on a global scale. The sources of data were selected following a hierarchical approach, mainly based on the criteria by Sleeswijk et al. (2008) and in accordance with the procedure proposed by Sala et al. (2015) (see "Section 2.1" for more details).

A complete list of data sources by groups of substances for each impact category is reported in Table 1.

Several methodological choices have been made in relation to the sources of data for building the inventories. Extrapolations, mainly temporal data-gap filling strategies, were applied for complementing the inventories in case of missing data, building on Sala et al. (2014) where possible. Moreover, assumptions have been made in order to map elementary flows retrieved from their original sources into those available in and consistent with the impact assessment models. Specific details on the extrapolation strategies are provided by impact category in "Section 2.1." 


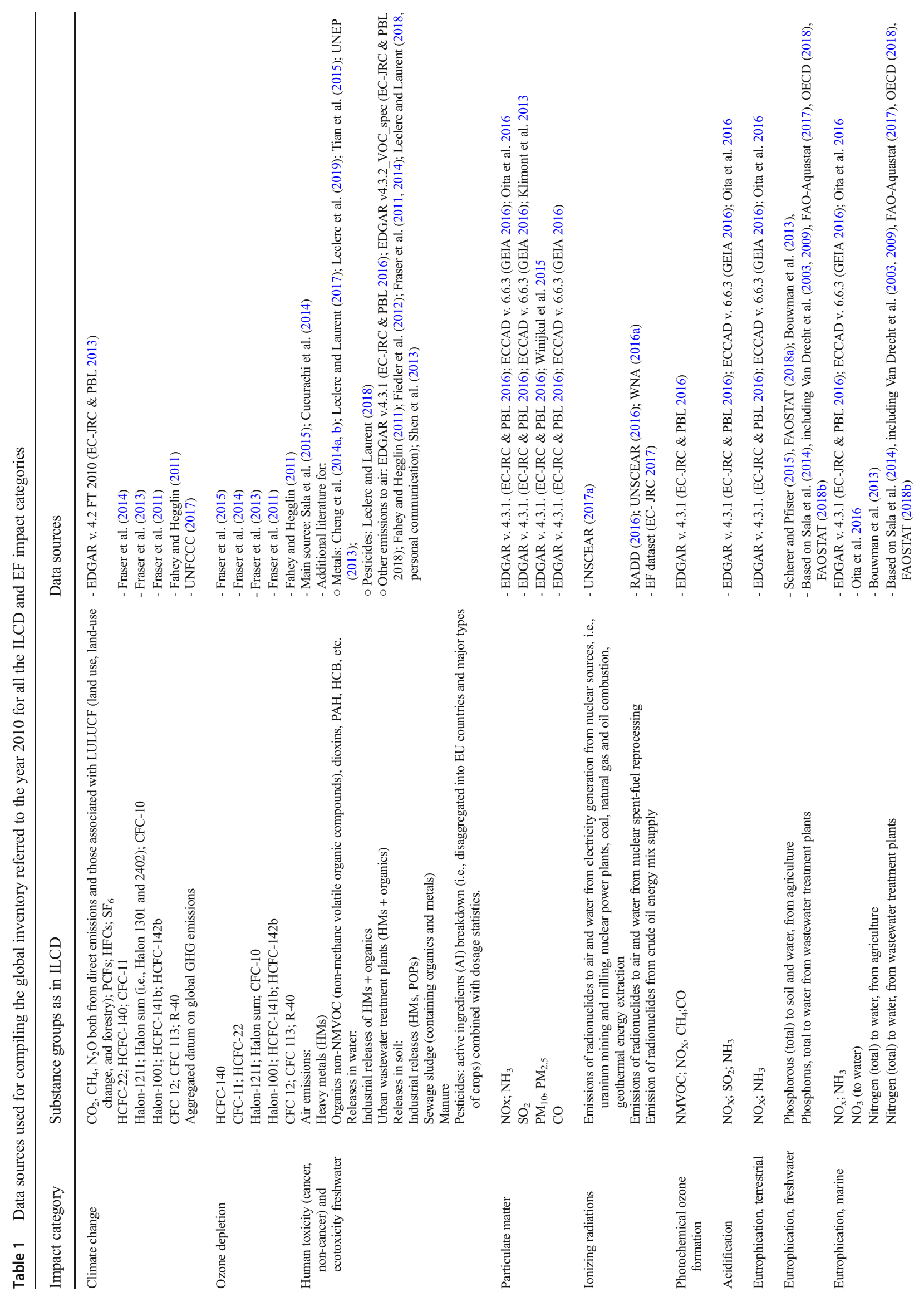


Concerning the methodology and, consequently, the results, some features and figures could differ from previous work on global normalization factors (i.e., Sala et al. 2016) due to calculation refining.

The inventory built for normalization has been characterized with both ILCD method and the EF method. Regarding ILCD, emissions and resource extraction data were classified into ILCD elementary flows, then characterized through the ILCD recommended impact assessment method v. 1.010 (EC-JRC 2011, 2012), by using characterization factors (CFs) at the midpoint. The ILCD method, developed by the European Commission's Joint Research Centre, entails the indicators and models recommended for LCIA in the European context. We accounted for the emissions to air, soil, and water without further detailing them into sub-compartments, mainly due to lack of detail in the majority of data sources. Therefore, generic CFs from ILCD, namely CFs which are not detailed in terms of emission sub-compartment (e.g., emitted to "unspecified" air, water, or soil), were applied to all inventoried flows although significant variability may be expected (see Benini and Sala 2016). The only exception is the particulate matter category, for which CFs detailed on the basis of the area of emission (i.e., urban or non-urban) could be matched with inventory data.

Additionally, a calculation of NFs using the EF method was performed. The EF method has evolved over time from the initial list of models (EC 2013a, b) to a reference package EF 2.0 (EC 2017; Fazio et al. 2018a), up to the reference package EF 3.0 (Zampori \& Pant 2019a, b; Fazio et al. 2018b). Details on the models used in the ILCD and in the different EF reference packages are reported in the ESM. In the EF, a number of impact categories, namely climate change, ozone depletion, three toxicity-related categories, particulate matter, land use, water use (water depletion according to ILCD), and resource use (resource depletion according to ILCD) have been updated (Sala et al. 2019). This was done by means of different and more recent models (compared to ILCD) underpinning the calculation of CFs, namely IPCC (2013) for climate change, WMO (2014) for ozone depletion, Saouter et al. (2018) for toxicity (both human and ecotoxicity), the model proposed by Fantke et al. (2016) for particulate matter, the soil quality loss index based on LANCA (Sala et al. 2019; De Laurentiis et al. 2019) for land use, AWARE model (Boulay et al. 2018) for water use, and ADP ultimate reserve model (van Oers et al. 2002) for resource use. To be compliant with the characterization methodology used in the EF reference package 3.0 that we used in this paper, we shaped the inventory for particulate matter, land use, and water use categories (see "Section 3.4," "Section 3.11," and "Section 3.12") and we used more detailed CFs than in ILCD, as follows: for particulate matter, we 
adopted CFs detailed by source height (i.e., the height of the stack for EF method); while for land use and water use, we adopted country-specific $\mathrm{CFs}$, instead of global default $\mathrm{CFs}$. From now on, when mentioning the impact categories in the text, we will use the nomenclature as proposed in the EF reference package 3.0.

\subsection{Criteria for data selection and data sources}

The global inventory of emissions and resources extracted in 2010 is mainly composed of statistics provided by international agencies and institutions, e.g., European Commission (EC), the Food and Agriculture Organization of the United Nations (FAO), the United States Geological Survey (USGS), and the Commonwealth Scientific and Industrial Research Organization (CSIRO) (see Sala et al. 2015 for a more detailed description of the data sources). Considering the broad variety of available statistical and scientific sources, the detailed hierarchical procedure proposed by Sala et al. (2015) based on the criteria of Sleeswijk et al. (2008) was used to guide the selection of inventory data, especially when alternative options for the same inventory flows were available. Generally, official statistics based on measured values or officially accepted models were preferred since they ensure higher robustness of the inventories. This was followed by (i) activity-based estimations, (ii) statistical proxies, and (iii) speculative assumptions based on reasonable correlation and/ or cause-effect models. All the identified data were gathered and comparisons were performed to understand the variability of the results. In the case of more than one plausible data source were available, the selection was based on the inventory better responding to higher levels of the abovementioned hierarchy. Moreover, robustness was evaluated in terms of both inventory coverage completeness and reliability (see "Section 2.2").

When data were missing for the reference year or the spatial scale needed for this study, assumptions or estimations were done to complement the dataset. Particularly, we adopted prioritization rules for data-gap filling when data were not available for 2010. Specifically, we retrieved (a) data related to years which were different from the reference one (e.g., preferably from 2008 to 2011, in any case within 20082014) coming from the primary source; (b) data for 2010 from a secondary source; and (c) if none of the previous alternatives was possible, data have been selected from a tertiary source.

In a few cases, it was not possible to strictly follow the procedure reported above, thus case-specific data-gap filling was needed, e.g., for the toxicity-related impact categories (i.e., human toxicity cancer and non-cancer, ecotoxicity), ionizing radiations, land use, and resource use (minerals and metals part only). The specific approaches are reported in "Section 3," for each impact category, and discussed together with the results.

\subsection{Robustness assessment of the calculated normalization factors}

A qualitative assessment of the completeness and robustness of the datasets used for building the inventories as well as the robustness of the impact assessment models underpinning the characterization of global impacts was performed for each impact category, according to specific criteria showed in Table 2 . The information behind this evaluation aims at drawing attention to the potential sources of uncertainty underlying the

Table 2 Criteria for evaluating the robustness of the global normalization factors

\begin{tabular}{|c|c|c|}
\hline Criteria and definitions & Score* & \\
\hline \multirow{3}{*}{$\begin{array}{l}\text { Inventory coverage completeness: extent to } \\
\text { which the inventory data cover the list of } \\
\text { elementary flows available in ILCD, for } \\
\text { each impact category }\end{array}$} & I & High (60 to $100 \%)$ \\
\hline & II & Medium (30 to $59 \%)$ \\
\hline & III & Low (0 to $29 \%)$ \\
\hline \multirow[t]{3}{*}{$\begin{array}{l}\text { Inventory robustness: quality of data, assessed } \\
\text { by considering both the combination of different } \\
\text { sources and the adoption of extrapolation strategies }\end{array}$} & $\mathrm{I}$ & $\begin{array}{l}\text { High (data from published datasets from official } \\
\text { data sources, subjected to a quality assurance } \\
\text { procedure and limited use of extrapolation methods, } \\
\text { i.e., }<20 \% \text { of the impact derived from extrapolation) }\end{array}$ \\
\hline & II & $\begin{array}{l}\text { Medium (non-publicly available or non-peer-reviewed } \\
\text { datasets and/or use of extrapolation methods for more } \\
\text { than } 20 \% \text { but less than } 80 \% \text { of the impact) }\end{array}$ \\
\hline & II & $\begin{array}{l}\text { Low (use of extrapolation methods for more than } \\
80 \% \text { of the impact) }\end{array}$ \\
\hline \multirow{3}{*}{$\begin{array}{l}\text { Robustness of the impact assessment method: } \\
\text { classification of the ILCD recommended } \\
\text { characterization models (EC-JRC 2011) } \\
\text { based on model quality }\end{array}$} & I & The model is recommended and satisfactory \\
\hline & II & The model is recommended but in need of some improvements \\
\hline & III & The model is recommended, but to be applied with caution \\
\hline
\end{tabular}

*Adapted from Sala et al. (2015) 
.

离

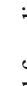

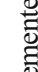

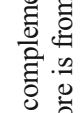

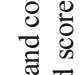

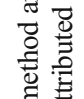

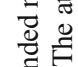

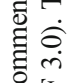

รั

을

言意

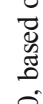

列$$
\text { है }
$$

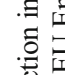

哉

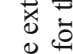

总

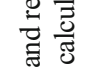

赔

를 च

형류

妥高

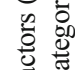

跣

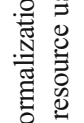

늘

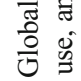

量高

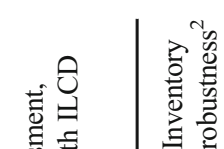

$-=\equiv$

$\because \Xi \equiv$

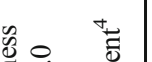

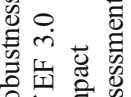

政

팡

은 艺崖

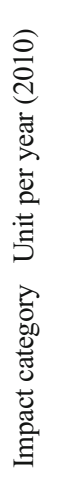

管$$
\text { 응 }
$$

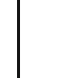

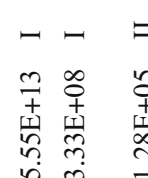

in ले

है

อุำ
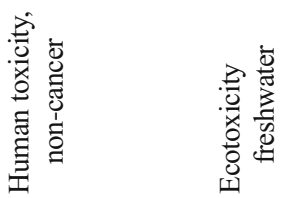

s

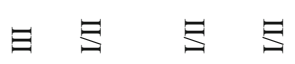

झ

s

$=\equiv \quad=$

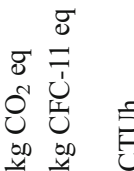

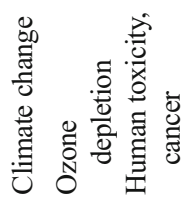

$\neg$ 音

罗

夆

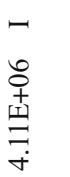

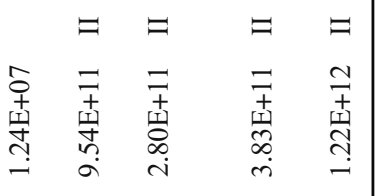

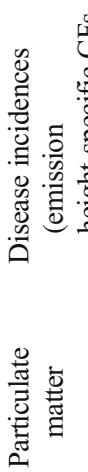

哓

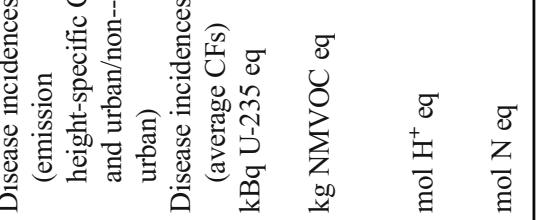

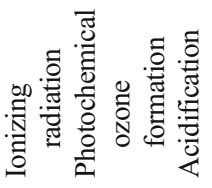

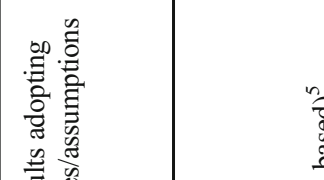

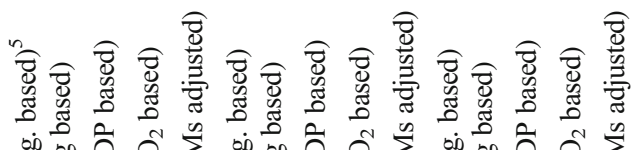

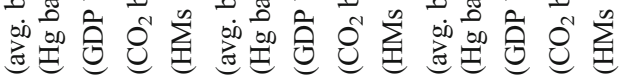

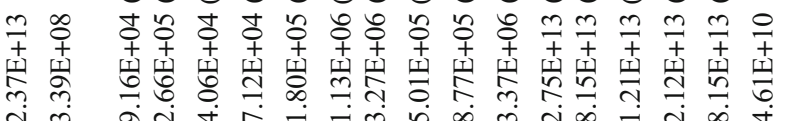

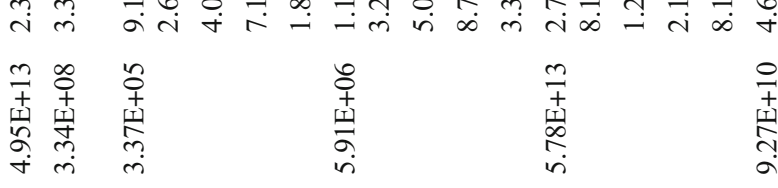

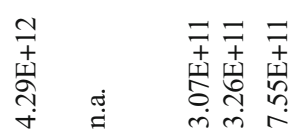

胥离

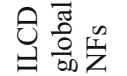

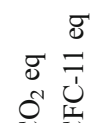

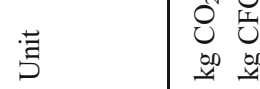

క5

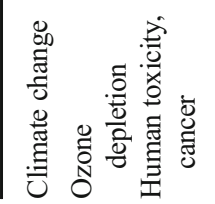

है

$\stackrel{0}{0}$

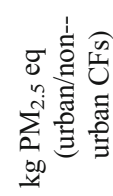

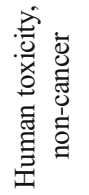

总

总 


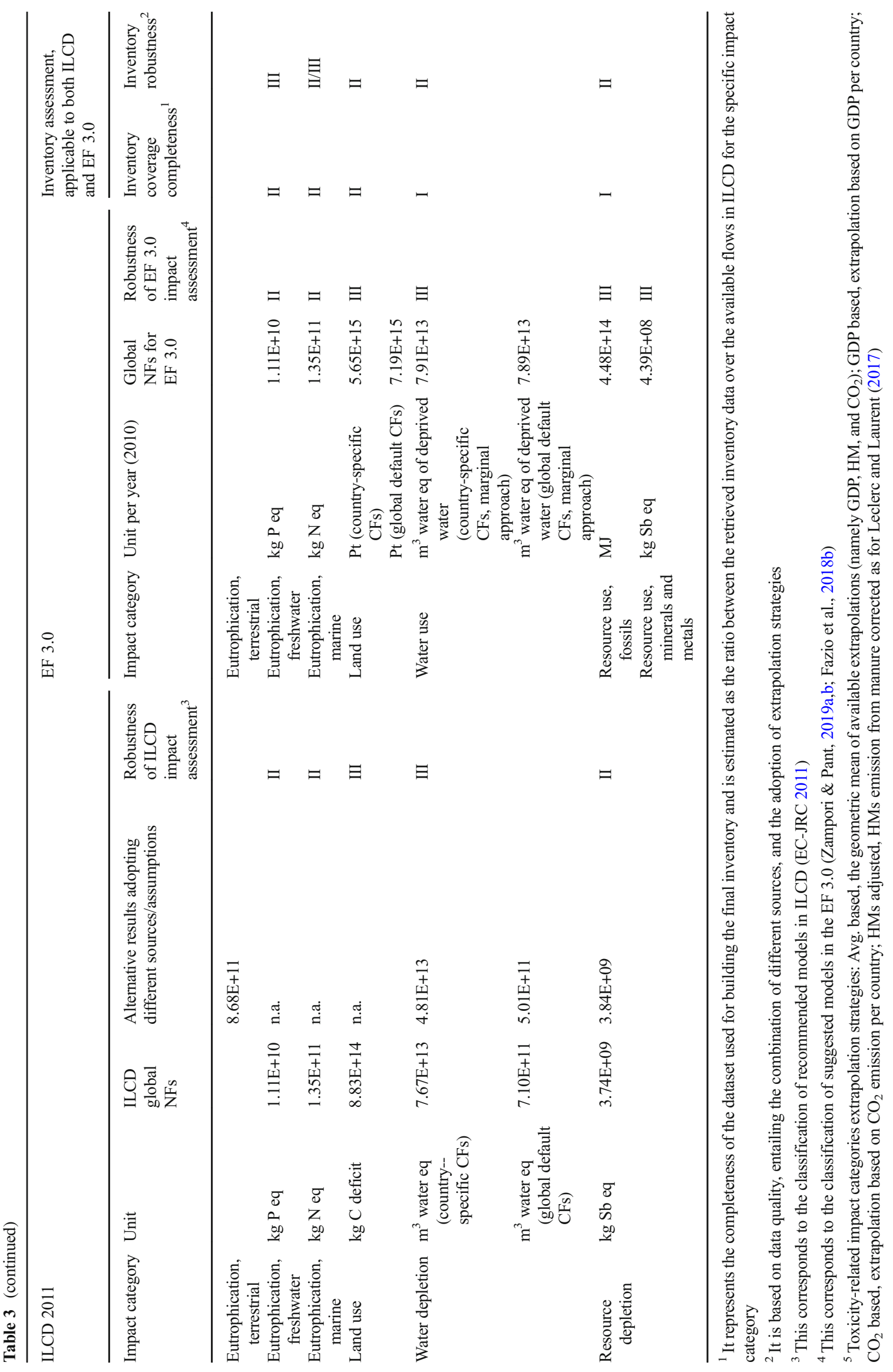


calculation of the normalization factors. Therefore, the robustness of the NFs is defined through expert judgment, by considering separately the following: inventory's completeness, robustness (based on data quality, entailing the combination of different sources and the adoption of extrapolation strategies), and the robustness of the impact assessment method (according to the recommendation from the ILCD (EC-JRC 2011)).

To increase the robustness of the final results, where a higher level of detail was available both in the inventory and in the adopted LCIA model, the calculation was made by means of data and CFs as much detailed as possible. In particular, when these details were available in the inventory, it was possible to use CFs specific for (i) countries, (ii) archetypes (i.e., urban or non-urban specification for air emission), and/or a certain height of the emission stacks. This was done primarily for calculating the normalization references of particulate matter, land use, and water use. Although the model for acidification provides as well country-specific CFs, the factors are for EU countries only, hampering the application at a global scale. Hence, the NF has been calculated for this impact category by adopting global default $\mathrm{CFs}$, avoiding the use of two different approaches (country specific for EU countries and global default for all the others). For the sake of completeness, for all the other abovementioned cases, an NF with global default CFs was calculated as well.

\section{Results and discussion}

Following the collection of data for compiling the global inventories and their mapping into elementary flows according to the ILCD nomenclature, the inventories were characterized by using ILCD CFs at the midpoint (EC-JRC 2012). Moreover, for a number of impact categories (i.e., climate change, particulate matter, human toxicity cancer and noncancer, ecotoxicity, freshwater eutrophication, land use, water use, resource use), an additional characterization was performed by using the LCIA models according to the EF reference package 3.0 (Zampori \& Pant 2019a, b; Fazio et al. 2018b; Sala et al. 2019).

Uncertainties in the calculation of the normalization factors may be due to different features, such as (i) the selection of the sources of data from different statistical database (Benini and Sala 2016), (ii) the use of data-gap filling procedures, and (iii) the specific features of the models estimating emission, since there could be differences in the chosen system boundaries between technosphere and ecosphere between inventory and impact assessment. The uncertainties related to the extrapolation procedures adopted in this study are detailed in "Section 4." A general overview of the results is presented in Table 3, while details on all the tested alternatives for both ILCD and EF are in the ESM.
In the following sections, for each impact category, we reported the results of the calculation of the NFs based on the global inventory for the year 2010. Each paragraph includes a section describing the global inventory sources and assumption and a section reporting the resulting normalization factors. The following aspects are detailed: (i) the specific data-gap filling procedure adopted for building the inventory; (ii) the coverage of the flows in the inventory with respect to the available flows in ILCD; (iii) the contribution of each flow to the final global impact; (iv) the main features leading to uncertainty; and (v) the normalization factors obtained by using different inventories characterized with ILCD and EF 3.0 method.

\subsection{Climate change}

\subsubsection{Global inventory}

The inventory for the climate change impact category is mainly based on EDGAR v. 4.2 FT2010 data for 2010 (EC-JRC \& PBL 2013). Notwithstanding UNFCCC provides emission data that should be preferred-according to the hierarchy in Sala et al. (2015) -EDGAR v. 4.2 FT2010 has been prioritized. Due to the high coverage of greenhouse gases (GHG) and countries, EDGAR was considered the most robust source in terms of completeness and representativeness of the world situation.

Adopting then EDGAR v.4.2 FT2010 (EC-JRC \& PBL 2013) as the main data source, figures for 215 countries and for 27 elementary flows were gathered. Concerning carbon dioxide emissions, the flows were split based on their source, namely fossils, biogenic, and from the land use/land use change and forestry sector (LULUCF). Since EDGAR do not account for LULUCF (which is included in the IPCC sector 5), we complemented the $\mathrm{CO}_{2}$ figure with the data from Houghton et al. (2012) as reported in the Global Carbon Atlas (GCA 2018), an initiative under the Global Carbon Project (GCP 2018). Then, to fill the remaining gaps in EDGAR v.4.2 FT2010 emission inventory, 2010 values for HCFC22, HCFC-140, and CFC-11 were taken from Fraser et al. (2014), while CFC-10, halon-1211, and the sum of halon1301 and halon-2402 from Fraser et al. (2013). Besides, 2008 data on halon-1001, HCFC-141b, and HCFC-142b were retrieved from Fraser et al. (2011), and on CFC-12, CFC-113, and R-40 from Fahey and Hegglin (2011), assuming that emissions remained unchanged or decreased during the years between 2008 and 2010 due to the 2007 adjustments to the Montreal Protocol (Montzka et al. 2014).

Concerning halons, we retrieved from Fraser et al. (2013) halon-1211 as single flow and the sum of halon-1211, 1301, and 2402 from which, by means of the simple subtraction operation, the sum of halon-1301 and 2402 could be obtained. Therefore, we adopted two options, according to the available 
data. Firstly, we took the sum of halon-1301, 2402, and 1211 as given in Fraser et al. (2013) and we characterized it by means of a CF obtained as the geometric mean of the three halon-related $\mathrm{CFs}$. Then, we compared it (i.e., $2.08 \mathrm{E}+10 \mathrm{~kg}$ $\mathrm{CO}_{2}$ eq) with the result of the characterization of halon-1211 taken as single flow and the characterization of the sum of halon-1301 and 2402 made with a CF obtained as the geometric mean the two halons-related CFs. The second option was retained $\left(1.80 \mathrm{E}+10 \mathrm{~kg} \mathrm{CO}_{2}\right.$ eq), which differs from the previous by ca. $15 \%$, since at least one flow is characterized with its own $\mathrm{CF}$, thus being more robust.

Concerning F-gases such as HCFC-141b and HCFC-142b, data were available in both Fraser et al. studies and in EDGAR v.4.2 (EC-JRC \& PBL 2011). However, since the figures in the two sources differ by at least one order of magnitude, a consistency check was carried out. Comparing the emissions data from EDGAR v.4.2 (EC-JRC \& PBL 2011) and Fraser et al. (2011), with other studies in literature, we attempted the validation of the two sources. The data on HCFC species retrieved from other studies (i.e., Montzka et al. 2014; Simmonds et al. 2016; see SI) were in greater accordance with Fraser et al. (2011). Hence, we prioritized this latter source for HCFC-141b and HCFC-142b values.

\subsubsection{Normalization factors}

The estimated NF for climate change according to the ILCD method stands at $4.95 \mathrm{E}+13 \mathrm{~kg} \mathrm{CO}_{2}$ eq. The inclusion of the additional flows from 2008 to fill the gaps does not bring relevant changes in the 2010 inventory. In fact, the characterized result without 2008 data would be $2 \%$ lower. According to the final choice of including 2008 figures, the inventory for climate change covers 40 substances ( 27 from EDGAR and 13 from other sources) out of 101 for which a CF is available in ILCD. Three substances dominate the overall impact, namely $\mathrm{CO}_{2}$ (70\%, mainly from burning fossil fuels), $\mathrm{CH}_{4}$ (17\%, of which two-third are from fossils), and $\mathrm{N}_{2} \mathrm{O}(6 \%)$. The remaining substances contribute to around $7 \%$ of the total global impact.

UNFCCC (2017) was explored as an alternative source. It reports GHG data, collected by both Annex I and non-Annex I parties, already characterized figures calculated using the global warming potential in 100 -year time horizon $\left(\mathrm{GWP}_{100}\right)$ factors as in IPCC 2007 . The related global value for climate change stands at $2.37 \mathrm{E}+13 \mathrm{~kg} \mathrm{CO}_{2}$ eq, which represents less than half of the ILCD NF estimated above. Although the UNFCCC value is based on CFs which are in line with the ILCD recommendations for LCIA, it was considered unrepresentative of the world situation because of its limited accounting of world countries. Specifically, UNFCCC covers 84 ISO countries, and some important GHG emission contributors, such as the USA, were not available. The value of $2.37 \mathrm{E}+13 \mathrm{~kg} \mathrm{CO}_{2}$ eq is then potentially underestimating global GHG emissions in 2010, and it is the result of the data available for 2010, plus the available data of countries missing in 2010 for which in close years, e.g., 2009-2012, a GHG emission figure was available. For example, for China data of 2012 were used as a proxy for 2010. As already reported, an additional normalization factor was calculated by means of the EF reference package 3.0 (Sala et al. 2019; Fazio et al. 2018b). It is based on the inventory presented above. However, it is characterized by using updated CFs from IPCC (2013), which includes also CO as emission. Updated CFs are generally higher than those adopted in the previous version (IPCC 2007). Hence, the resulting final figure is nearly $10 \%$ higher than the global normalization factor calculated above, i.e., $5.55 \mathrm{E}+13$ vs $4.95 \mathrm{E}+13 \mathrm{~kg} \mathrm{CO}_{2}$ eq.

\subsection{Ozone depletion}

\subsubsection{Global inventory}

As for climate change, EDGAR v.4.2 FT2010 data (EC-JRC \& PBL 2013) were considered due to their wide coverage. Nevertheless, data for ozone-depleting substances were not reported for 2010. Therefore, the inventory related to ozonedepleting substances, specifically CFC-10, CFC-11, HCFC22, and HCFC-140, was retrieved from Fraser et al. (2013, 2014, 2015). Figures for halons, as for climate change, were retrieved from Fraser et al. (2013) and the same characterization procedure was adopted. Due to the lack of several emission data for the year 2010, temporal data-gap filling procedures were applied to some substances, namely halon-1001, HCFC$141 \mathrm{~b}$, and HCFC-142b, by using the values available for 2008 (Fraser et al. 2011), as for climate change. Additionally, the inventory has been complemented with 2008 data of CFC-12, CFC-113, and R-40 from Fahey and Hegglin (2011). The final inventory is composed mainly by data from one source, namely the series of papers of Fraser et al. (2013, 2014, 2015). This allows maintaining the consistency with the hierarchy we proposed in "Section 2" (specifically, preferring data from a year which is different from the reference, but coming from the primary source). The data for the final inventory are available for ten flows out of 23 for which there is a CF in the ILCD, without accounting for the halon-aggregated flow.

\subsubsection{Normalization factors}

The NF for ozone depletion stands at 3.34E+08 kg CFC-11 equivalent. The highest contributors are CFC-11 and CFC-12. Each of them is responsible for nearly $22 \%$ of the global impact, followed by R-40 (or methyl chloride) and CFC-10 which cover respectively $18 \%$ and $13 \%$ of the overall impact. The normalization factor at a global scale was calculated also by means of the EF reference package 3.0, which adopt the most up-to-date version of the model for ozone depletion 
(WMO 2014). EF result stands at 3.33E+08 kg CFC-11 eq, a figure which is slightly lower $(<1 \%)$ than the result for ILCD.

Generally, uncertainties in the estimation of the global NF for ozone depletion are considered quite high, mostly because the majority of the substances contributing to ozone depletion impacts are not accounted in the inventory, leading to limited completeness of the substances coverage. In fact, limited data on ozone-depleting substances are available in the scientific literature, with particular regards to HCFCs from developing countries which in 2008 accounted for $74 \%$ and $73 \%$ of total ODP-weighted HCFC consumption and production, respectively (UNEP 2010). Furthermore, the application of extrapolation strategies for filling the temporal data gap led to rather low robustness of the inventory for this category.

\subsection{Human toxicity (cancer and non-cancer) and ecotoxicity freshwater}

\subsubsection{Global inventory}

Inventorizing chemical emission is considered a challenging task, due to the huge number of substances emitted and the complexity of proper characterization. Building on the work of Sala et al. (2015) and Cucurachi et al. (2014), a new global inventory has been compiled and characterized with both ILCD and EF 3.0 (with the CFs as provided by Saouter et al. 2018). The inventory developed here was the result of identifying adequate upscaling factors and of complementing previous inventories with more updated data where available.

Firstly, a global NF was built upscaling the EU inventory as available in Sala et al. (2015), by using the upscaling factor 14.12 derived from Cucurachi et al. (2014), with further refinements. This factor was deemed the best for taking into account the role of heavy metals, being the ratio between the global extrapolated reference for $\mathrm{Hg}$ emissions and the related $\mathrm{EU}$ value reported by Cucurachi et al. (2014) for human toxicity, cancer.

For refining or complementing the inventory from Sala et al. (2015), additional data have been retrieved from current literature for several substances and specific upscaling factors adopted, as follows.

Metals Emissions to soil of metals proceeding from manure (arsenic, cadmium, chromium, copper, lead, mercury, nickel, zinc) were taken from Leclerc and Laurent (2017). Emissions to air of chromium, lead, and antimony are based on the upscale of Chinese records (Cheng et al. 2014a; Tian et al. 2015), by means of the Chinese share of global electricity generated from coal (37\%, IEA 2018). Emissions to air of arsenic, cobalt, manganese, and selenium were upscaled from Chinese records (Cheng et al. 2014b; Tian et al. 2015) to the global value by considering the Chinese share of global mercury emissions (31\%, UNEP 2013). Emissions of mercury to both air and water proceed from UNEP (2013). Emissions to water of aluminum come from Leclerc and Laurent (2018). Emissions to water of arsenic, cadmium, lead, and selenium are based on the upscale of EU inventory from Sala et al. (2015) by considering the European share of global emissions to air, assumed to be the same as to water. Finally, emissions to water of cobalt, copper, and manganese were taken from the upscale of the updated EU inventory of Leclerc et al. (2019) by factor 14.12 derived from Cucurachi et al. (2014).

Pesticides The EU inventory of pesticides in Sala et al. (2015) was replaced by its most up-to-date version from Leclerc et al. (2019). The inventory of Leclerc et al. (2019) was complemented with emissions from three additional EU countries (Bulgaria, Croatia, and Romania, previously neglected) and upscaled based on the ratio between European and global agricultural land (3.84\%, Faragò et al. 2019).

Other emissions to air Global emissions to air for 20 substances (e.g., HFC, HCFC) were retrieved from the available literature, and they were already inventoried as contributors to climate change and ozone depletion. For other 30 substances (e.g., dioxins, furans, BTEX), global emissions to air were retrieved from other studies (Shen et al. 2013; Fiedler et al. 2012; EC-JRC \& PBL 2018; Leclerc and Laurent 2018).

After its classification into the ILCD- (EC-JRC 2011, 2012) and the EF-compliant elementary flows (Saouter et al. 2018), the final inventory was characterized. For those substances and groups for which there was no possibility to be directly mapped into either an existing ILCD- or EFcompliant elementary flow, ad hoc CFs were calculated in order to improve the coverage (as reported in the ESM). Furthermore, for the EF NF, acknowledging the potential underestimation of the NF especially for ecotoxicity freshwater due to a limited list of substances, the unmapped pesticides were characterized by means of a proxy CF derived as the average of the available CFs for pesticides in the normalization inventory.

Specifically, for the ILCD, several options for the inventory have been tested and normalization references calculated (reported as alternative results in Table 3). Those options are based on different combination of the original upscaling factors of Cucurachi as well as specific changes in metals according to Leclerc and Laurent (2017). Details are provided in the ESM.

Due to the incompleteness of the previous sets, hereinafter only the results of the refined inventory developed in this study are reported.

\subsubsection{Normalization factors}

The ILCD-based global NFs for the three toxicity impact categories stand at 5.78E+13 CTUe for ecotoxicity; 3.37E+05 CTUh for human toxicity, cancer; and 5.91E+06 CTUh for 
human toxicity, non-cancer. While, the EF-based global NFs stand at 2.94E+14 CTUe for ecotoxicity; 1.28E+05 CTUh for human toxicity, cancer; and 1.59E+06 CTUh for human toxicity, non-cancer. The difference between the two methods in terms of absolute values and flows contribution is mainly linked to the substance coverage of each method and the different effect factors underpinning the CFs. In fact, the EF method covers a higher number of substances than ILCD, and the EF CFs for ecotoxicity and human toxicity, noncancer are based on lower ecotoxicological endpoints (namely the effective concentration (EC) EC20 instead of EC50 as used in the original USEtox ${ }^{\mathrm{TM}}$ model as applied in ILCD), thus leading to higher CFs. Furthermore, EF CFs are weighted according to the nature of the substances (organic, inorganic, metal) (see Saouter et al. 2018 for more details). The uncertainties in the calculation of the global NFs are high and derive from different sources, namely the large use of extrapolation strategies both behind the EU inventory (as highlighted by Cucurachi et al. 2014; Sala et al. 2015) and behind its upscale to the whole world, the reliability of the underpinning data sources and the mapping of emissions into compliant elementary flows.

\subsection{Particulate matter}

\subsubsection{Global inventory}

Data on emissions relevant for the particulate matter (PM) impact category were retrieved from different sources, namely EDGAR v.4.3.1 (EC-JRC \& PBL 2016), MACCIty database distributed by ECCAD v.6.6.3 (GEIA 2016), and papers (Oita et al. 2016; Winijkul et al. 2015; Klimont et al. 2013). The data sources present a very different level of inventory coverage. EDGAR v.4.3.1 was selected as an exclusive data source for this impact category, because of two main features: completeness of the coverage and emission compartment specificity. Regarding completeness, inventory data taken from EDGAR v.4.3.1 are available for five out of nine flows for which there is a CF in the ILCD. The other sources vary from a coverage of one (i.e., Klimont et al. 2013) to four flows at maximum (i.e., ECCAD v.6.6.3 from GEIA 2016), thus limiting the completeness. Regarding the emission compartment specificity, EDGAR database classifies emissions according to the IPCC sector, allowing defining the height for each sector following the definition in the IPCC guidelines (IPCC 2006) (i.e., close to ground, low/high/very high stacks, lower stratosphere, and upper troposphere), as well as carrying out a separation between "urban" and "non-urban" emissions according to the population fraction living in urban areas and rural areas in 2010 (UNDESA 2012). This classification was especially useful for the calculation based on the EF 3.0 (Sala et al. 2019; Fazio et al. 2018b), since the model for PM (Fantke et al. 2016) provides CFs differentiated according to the abovementioned emission height classes. These aspects led to a stronger result in terms of completeness and robustness. Concerning ILCD v.1.010 (EC-JRC 2012), the NF is the result of using CFs for urban and non-urban emissions without further specificity, since the model for PM misses the differentiation based on emission height.

Although data on both $\mathrm{PM}_{10}$ and $\mathrm{PM}_{2.5}$ were retrieved and the latter is a fraction of the former, only $\mathrm{PM}_{2.5}$ has been characterized following the modeling rules of the method adopted, so to avoid double counting. In fact, according to Humbert (2009), $\mathrm{PM}_{2.5}$ represents the only responsible fraction for the health impacts due to $\mathrm{PM}_{10}$ exposure.

\subsubsection{Normalization factors}

The global NF built on the inventory from EDGAR v.4.3.1 and obtained by means of ILCD (EC-JRC 2012) is 9.27E+ $10 \mathrm{~kg} \mathrm{PM}_{2.5}$ equivalents. The highest contributor to this impact category is $\mathrm{PM}_{2.5}$ covering $88 \%$ of the overall impact, distantly followed by $\mathrm{SO}_{2}(7 \%)$ and $\mathrm{NH}_{3}$ (almost $4 \%$ ).

Overall, the characterized figures for each elementary flow from all the different data sources appear to be consistent and comparable with each other in terms of the magnitude of their impact. Specifically, in some cases as for $\mathrm{SO}_{2}$ and $\mathrm{CO}$ flows, values are very close one to the other. The exception is represented by the flow of $\mathrm{NO}_{\mathrm{x}}$ whose characterized figures span from 2.53E+08 (Oita et al. 2016) to $8.15+08 \mathrm{~kg} \mathrm{PM}_{2.5}$ equivalent (EDGAR v.4.3.1). This is mainly due to the fact that, while EDGAR v.4.3.1 database covers emissions for several sectors (i.e., energy industry, transport, chemical industry, manure management, agricultural waste burning, solid waste disposal), Oita et al. (2016) provide data on anthropogenic emissions of nitrogen compounds to the atmosphere mainly coming from agriculture and a few other sectors (i.e., energy generation and transport).

The normalization factor at a global scale was calculated with the EF reference package 3.0 as well, on the basis of the same inventory built on EDGAR and the PM model of Fantke et al. (2016). The resulting NF is $4.11 \mathrm{E}+06$ disease incidences, and it is not comparable with the previous one because of the different unit (i.e., $\mathrm{kg} \mathrm{PM}_{2.5}$ eq).

\section{5 lonizing radiation}

\subsubsection{Global inventory}

The inventory for ionizing radiation category was built by combining the emissions of radionuclides to air and water from a number of sectors, including nuclear power plants; uranium mining and milling; coal, natural gas, and oil combustion; geothermal energy extraction for global electricity generation (UNSCEAR 2017a); crude oil extraction (EC- 
JRC 2017); and nuclear spent-fuel reprocessing plants (RADD 2016; UNSCEAR 2016; WNA 2016a).

Firstly, for each radionuclide emission reported in UNSCEAR (2017a), the radionuclide discharge per gigawatt per year of electricity generated $(\mathrm{TBq} / \mathrm{GW}$ a) was retrieved and multiplied by the total GW a of electricity generated in 2010 at global scale from the specific sector (e.g., uranium mining and milling, nuclear power plant operation). Specifically, for nuclear power plants, two different approaches have been used, namely (i) the radionuclide discharge of each reactor type (e.g., pressurized water reactor, boiled water reactor) has been multiplied by the GW a of electricity generated in 2010 by each specific reactor type and (ii) an average discharge (arithmetic mean) has been calculated for each radionuclide (carbon-14 to air, hydrogen-3 to air and to water, and iodine-131 to air) and multiplied by the global GW a generated in 2010 from nuclear power plants. In this way, we obtained two worldwide inventories of radionuclides emitted in 2010 (expressed in $\mathrm{kBq}$ ) that were multiplied by the corresponding CFs in order to get the characterized results for each sector.

Secondly, the emissions of ionizing radiations to air and water due to nuclear spent-fuel reprocessing activities were taken for the reprocessing plants of the UK and France, for the reference year 2010. Radioactive emissions from reprocessing activities in India and Russia were derived from the UK and France data, respectively, according to the reprocessing technology employed and assuming the full capacity of the reprocessing plant, and then characterized. The global NF for ionizing radiations is given by the sum of the characterized results for each sector.

It is important to highlight that this inventory considers only routinary emissions, not accidents and that the figure would change significantly otherwise. Moreover, not taking into account, radiations from non-energy-related activities (e.g., phosphate and ceramics industry, gypsum end-of-life, radio-chemicals production, and research facilities) could lead to an underestimation of the global NF. Inventory data were available for 21 elementary flows out of 42 for which there is a CF in ILCD, thus contributing to medium-high inventory coverage. Data on emissions from reprocessing plants are available also for several shutdown plants (ENS 2016), such as Karlsruhe (Germany), Dounreay (UK), and Tokai (Japan). Due to their ceased activity and to their very low contribution to the total impacts (less than 1\%), those were not taken into account for the calculation of NFs.

\subsubsection{Normalization factors}

The global normalization factors for ionizing radiations stand at $9.54 \mathrm{E}+11 \mathrm{kBq} \mathrm{U}-235 \mathrm{eq}$ (by accounting for the specific radionuclide discharge and energy generated per nuclear reactor type) and 4.29E+12 kBq U-235 eq (by using an average discharge for each radionuclide emitted and global GW a from nuclear power plants). The difference between the two proposed values comes from the fact that the second option is based on an average value ( $1.305 \mathrm{TBq} \mathrm{C}-14 / \mathrm{GW}$ a) that makes only the radionuclide discharge count, thus converging towards the figure related to the type of reactor with the highest release. Whereas by accounting also for the differences in the actual electricity production of the specific reactor types as in the first option, the final result is reflecting the relative share of the specific emission profile, leading to a much lower weighted emission factor (0.194 TBq C-14/GW a). The details of this analysis are reported in the ESM, in the sections dedicated to ionizing radiation.

The first calculation (bottom-up approach) is more accurate and robust since it accounts for the specific features of each reactor type. On the other hand, the second option is in line with preceding studies based on an average emission value (van Oers 2015). However, the underpinning emission intensity in Van Oers (2015), namely 8.4E+04 MBq C-14/TWh (as reported in Dreicer et al. 1995), differs from the figure used in the present study (e.g., 1.49E+05 MBq C-14/TWh as average) calculated by using data retrieved from UNSCEAR (2017a) report.

In both cases, operating nuclear power plants, followed by spent-fuel reprocessing activities, contribute the most to the overall figure. This is likely due to the high richness of the underpinning inventory in terms of a number of available elementary flows, compared to the other sources of radionuclides, e.g., natural gas and oil combustion for which only radon-222 is inventoried. The major contributors to the global impact are the emissions to air of carbon-14 (e.g., almost $86 \%$ in the first option presented above), distantly followed by cesium-137 to water (around 7\%) and radon-222 to air (about $3 \%$ ). At the inventory level, radon-222 dominates with a high level of emission registered for all the activities. However, the CF of radon-222 is very low compared to the one of carbon14 , leading to a high contribution of this latter to the overall impact. Comparing both the characterization made by using ILCD, which is based on the recommended model developed by Frischknecht et al. (2000) (egalitarian perspective, time horizon 100,000 years), with a characterization based on the same model with an individualist perspective (time horizon 100 years), the individualist-based NFs are lower than the others by almost one order of magnitude, mainly due to a variation of one order of magnitude in the CF of carbon-14 to air, which anyway remains the main contributor followed by cesium-137 to water. In fact, among the long-lived globally dispersed radionuclides periodically assessed (i.e., hydrogen3 , carbon-14, krypton-85, and iodine-129), carbon-14 represents the largest contributor to the exposure from global dispersion of long-lived radionuclides discharged from reprocessing of nuclear spent-fuel and is a significant contributor to the exposure resulting from the operation of nuclear reactors (UNSCEAR 2017b). 
Uncertainties in the calculation of the global reference for ionizing radiation derives from several aspects, namely the selection of characterization factors; the extrapolation of Indian and Russian emission profiles for the spent-fuel reprocessing-related inventory (as explained in the Section 2); the lack of accounting for the emissions from non-energy-related activities, such as phosphate industry and ceramics industries (UNSCEAR 2010) (although apparently emissions from such sectors are not significant contributors to the global NF for ionizing radiations according to the results obtained by the analysis of, e.g., several processes related to phosphate rock mining for fertilizer production); and the level of details of the emission profile for nuclear power plants. In addition, emissions of radionuclides stemming from electricity production due to mining activities, coal, natural gas, and oil combustion, and geothermal energy use are currently poorly reported in the literature. Further improvements in the inventory should aim at filling these gaps. Moreover, there is a need to search for more detailed and precise data, in order to avoid a wide number of assumptions and extrapolations.

\subsection{Photochemical ozone formation}

\subsubsection{Global inventory}

Inventory data for photochemical ozone formation were taken from EDGAR v. 4.3 .1 (EC-JRC \& PBL 2016) and were available for four ILCD flows out of 132 currently characterized in the ILCD.

The group of non-methane volatile organic compounds (NMVOC) represents the key issue from the inventory side. This group includes a high number of substances known to contribute to photochemical ozone formation. An aggregated value for NMVOC has been retrieved from the EDGAR database (EC-JRC \& PBL 2016. Alternatively, according to the methodology developed by Laurent and Hauschild (2014), a substance breakdown could have been done, using available speciation profiles based on sectoral activity data. The breakdown strategy would allow having a more comprehensive and precise inventory based on a greater number of elementary flows, characterizing the impact of each substance by using their specific CF, also available in ILCD. However, according to the calculations made by Sala et al. (2015) for the EU27, the characterized result for NMVOC based on breakdown procedure remains relatively unchanged with respect to the characterized value obtained by using total NMVOC aggregated value (meaning no-breakdown procedures). Unlike the EU27 emissions, at a global level, the values for single NMVOC flows are missing and information on their speciation profiles are not readily available in the current literature. Therefore, only the aggregated value for NMVOC has been retrieved, leading to very low robustness and coverage completeness of the inventory.

\subsubsection{Normalization factor}

The final NF stands at $2.80 \mathrm{E}+11 \mathrm{~kg}$ NMVOC equivalents. An underestimation could occur according to the inventory limitation described above. The overall impact is driven by NMVOC (around 48\%), followed by nitrogen oxides (40\%), carbon monoxide $(10 \%)$, and methane $(<2 \%)$.

\subsection{Acidification}

\subsubsection{Global inventory}

The collection of data for building the global inventory for acidification was guided by the main assumptions of the characterization model by Posch et al. (2008) and its definition of system boundaries. It was then possible to retrieve three global inventories taken from (i) EDGAR v.4.3.1 (EC-JRC \& PBL 2016), (ii) ECCAD v.6.6.3 (GEIA 2016), and (iii) Oita et al. (2016). All the alternative inventories cover the same three flows (i.e., $\mathrm{NO}_{\mathrm{x}}, \mathrm{NH}_{3}$, and $\mathrm{SO}_{2}$ ) out of seven for which there is a $\mathrm{CF}$ in the ILCD, contributing to a medium level of coverage completeness.

\subsubsection{Normalization factors}

Based on the three retrieved global inventories, the estimated NFs for acidification stand at (i) $3.83 \mathrm{E}+11$, (ii) $3.07 \mathrm{E}+11$, and (iii) $3.26 \mathrm{E}+11 \mathrm{~mol} \mathrm{H}^{+}$equivalents. As EDGAR v.4.3.1 (ECJRC \& PBL 2016) database covers emissions coming from a broader range of sectors, included manure management, it was selected as the final option. Comparing the figures across the characterized inventories, it is possible to see that the three substances do not contribute with the same magnitude to the overall impact. For instance, for each characterized inventory, the flow of nitrogen oxides represents the minor contributor as acidifying substance, although figures vary within a range from 8 to $22 \%$, instead, $\mathrm{SO}_{2}$ and $\mathrm{NH}_{3}$ represent the first or the second most important contributor to acidification depending on the source. According to the relatively limited difference among the final scores (less than 20\%), and to the higher level of completeness in terms of covered emission sectors, EDGAR v.4.3.1 (EC-JRC \& PBL 2016) has been selected as a data source, without additional extrapolations. On that basis, the robustness of the inventory underneath this impact category is judged to be medium.

The CFs that characterize the emissions in the acidification and eutrophication categories reflect the assumption that the inventory model is already accounting for the initial fate of macronutrients in soil and water. The modeling of the emissions to agricultural soil, particularly regarding the nutrient fate modeling, and its consistency with the boundaries between technosphere and ecosphere has been questioned in literature. In fact, the question around drawing the borders 
between the economy and the natural environment in a consistent and meaningful way is a gray area in LCA, especially relevant to agricultural systems. Additionally, the discussion on the accounting of nutrients to soil is still ongoing, due to the fact that agricultural soil is often seen as belonging to the technosphere. Depending on the fate modeling at the inventory stage, the elementary flow may be addressed to as total direct emission to agricultural soil or just as a fraction that will leave the soil thus considering at the inventory level the fate into the environmental compartments.

\subsection{Eutrophication, terrestrial}

\subsubsection{Global inventory}

As for acidification, for the terrestrial eutrophication impact category, three comparable inventories for the year 2010 were taken from (i) EDGAR v.4.3.1 (EC-JRC \& PBL 2016), (ii) ECCAD v6.6.3 (GEIA 2016), and (iii) Oita et al. (2016). All the options cover the same two flows (i.e., $\mathrm{NO}_{\mathrm{x}}$ and $\mathrm{NH}_{3}$ ) out of seven for which there is a CF in the ILCD, thus limiting the completeness of the inventory coverage. However, EDGAR v.4.3.1 (EC-JRC \& PBL 2016) database covers emissions coming from a broader range of sectors compared with the other data sources. Therefore, it has been selected as source of data.

\subsubsection{Normalization factors}

The estimated NFs are (i) $1.22 \mathrm{E}+12$, (ii) $8.68 \mathrm{E}+11$, and (iii) $7.55 \mathrm{E}+11$ mol N equivalents, respectively. The first option, based on EDGAR v.4.3.1 (EC-JRC \& PBL 2016) is recommended for its use with ILCD and compatible methods' results due to the higher level of completeness of the underpinning inventory. The other two options are lower than EDGAR's one (28\% for option (ii) and $38 \%$ for option (iii)). Comparing the figures across the characterized inventories, in at least two out of three inventories (i.e., EDGAR v.4.3.1 and ECCAD v.6.6.3), the flows related to $\mathrm{NH}_{3}$ and $\mathrm{NO}_{x}$ approximately contribute with the same magnitude (i.e., $61-65 \%$ and $39-35 \%$ respectively) to the overall impact. Generally, $\mathrm{NH}_{3}$ represents the major contributor to terrestrial eutrophicationrelated impacts, while $\mathrm{NO}_{\mathrm{x}}$ represents the flow that less contributes to the overall impact.

\subsection{Eutrophication, freshwater}

\subsubsection{Global inventory}

Similar to acidification, the collection of data for building the inventory of freshwater eutrophication was guided by the assumption of the characterization model by Struijs et al. (2009) and its definition of system boundaries. Further elaborations were then needed. Data on phosphorus emissions following manure and fertilizer application to both soil and water and emissions of phosphorus to water from wastewater treatment plants (WWTP) were retrieved.

The data on the global emission of phosphorus from agriculture were not directly available for the reference year. However, different options were available in the literature. The emissions of phosphorus (P) to soil and water were firstly collected from Bouwman et al. (2013), where a comprehensive inventory of global $\mathrm{P}$ availability in the agricultural systems is presented, covering the years $1900,1950,2000$, and the possible future changes in 2050, based on the United Nations projection (IAASTD scenario from McIntyre et al. 2009). According to the linear growth of global P amount underlined by the study, a linear interpolation was performed for calculating the annual increase of phosphorus at a global level between the years 2000 and 2050. The figures related to 2010, namely global $P$ input from manure, global $P$ input from fertilizers, and global P runoff (i.e., the only pathway which is assumed to move $\mathrm{P}$ to water sources), were punctually estimated and mapped into ILCD elementary flows. Particularly, they were respectively mapped as "manure, applied ( $\mathrm{P}$ component)," "fertilizer, applied (P component)," and "phosphorus, total (to water)"thus being compliant with ILCD. According to FAOSTAT (2016), the global production and consumption of both fertilizers (in terms of $\mathrm{P}_{2} \mathrm{O}_{5}$ and $\mathrm{N}$ ) and manure (expressed as $\mathrm{N}$ ) present a linear trend over a 12year period, i.e., 2002-2014. This feature would justify and validate the extrapolation procedure based on the data from Bouwman et al. (2013).

Additional emissions of phosphorus to water were collected from Scherer and Pfister (2015). The authors provide an estimation of crop-specific average emissions of $\mathrm{P}$ to the aquatic environment ( $\mathrm{kg} \mathrm{P} / \mathrm{kg}$ crop) for 169 among crop species and groups. A second inventory was thus elaborated for the emissions of this macronutrient to water combining the data of Scherer and Pfister (2015) and the data of global crop production in 2010 from FAOSTAT (2018a) (see ESM for calculation). This latter calculation has been retained as inventory for the global NF, as it is based on measured data considered less uncertain compared to the linear extrapolation from Bouwman et al. (2013).

Besides the emission of $\mathrm{P}$ to water related to the agricultural system, total $\mathrm{P}$ emissions from wastewater treatment plants (WWTP) were retrieved following the procedure explained in Sala et al. (2014). This was based on the methodology developed by van Drecht et al. (2003, 2009). For the non-European countries, data on the production and treatment of wastewater were retrieved from FAO-Aquastat (2018), the population connected to WWTP from OECD (2018), and the protein intake from FAOSTAT (2018b). Inventory data were available for three flows out of the seven flows for which ILCD provides a CF. In fact, values for phosphate and phosphoric acid, 
both to water and to soil, were missing in the available statistics and literature, limiting the completeness of the inventory.

\subsubsection{Normalization factor}

The characterized result stands at $1.11 \mathrm{E}+10 \mathrm{~kg} P$ equivalents, of which approximately $71 \%$ is due to emissions of phosphorous to water. The remaining impact derives from phosphorous emissions to soil, following the application of animal manure and fertilizer.

\subsection{Eutrophication, marine}

\subsubsection{Global inventory}

The inventory for marine eutrophication was built on statistics of nitrogen compounds taken from various sources, as reported in ESM. According to the prioritization of sources proposed by Sala et al. (2015) and maintaining the consistency with the choices made for the other impact categories (e.g., priority is given to EDGAR v.4.3.1 over ECCAD v.6.6.3 because of its major completeness in sector coverage), several assumptions were made for compiling the final inventory. Data were collected for four ILCD flows out of 10 for marine eutrophication. As explained in the previous section for phosphorus, the figure of global nitrogen leaching and runoff for 2010 was punctually estimated from the study of Bouwman et al. (2013) and mapped into the ILCD elementary flow "nitrogen total (to water)." Being this figure referred only to emissions from the agriculture system, it was complemented by means of the total nitrogen emissions from wastewater treatment plants. As for freshwater eutrophication, we followed the same procedure explained in Sala et al. (2014), based on the methodology developed by van Drecht et al. (2003, 2009), using data from FAO-Aquastat (2018), OECD (2018), and FAOSTAT (2018b).

\subsubsection{Normalization factors}

The finally selected NF, based on the so-called final global inventory in ESM, stands at $1.35 \mathrm{E}+11 \mathrm{~kg} \mathrm{~N}$ equivalents. The characterization of this inventory reveals that the highest contributor to this impact category is $\mathrm{N}$ total covering $51 \%$ of the overall impact (44\% of which comes from agriculture), distantly followed by $\mathrm{NO}_{\mathrm{x}}(33 \%) . \mathrm{NH}_{3}$ and nitrate, summed together, cover about $17 \%$ of the global impact.

Overall, the figures provided by all data sources appear to be rather consistent with each other in terms of impact. As already explained in "Section 3.4," the differences depend on the extent to which the data sources cover emissions from different sectors. This is especially valid in the case of nitrogen oxides, whose value span from 1.36E+10 (Oita et al. 2016) to $4.39 \mathrm{E}+10 \mathrm{~kg} \mathrm{~N}$ equivalent (EDGAR v.4.3.1).
Uncertainty in the estimation of the global NF for marine eutrophication may derive from different aspects, such as the choice of combining different sources and the still limited completeness of the inventory coverage.

\subsection{Land use}

\subsubsection{Global inventory}

The inventory for land use was developed by Faragò et al. (2019), based on a number of criteria and extrapolation strategies. Generally, the approach of Faragò and colleagues was consistent with the main aspects of this study: (a) global coverage, (b) spatially differentiation at the country level, (c) land use occupation and transformation flows, (d) consistency with the reference year of 2010. In fact, data concerning 13 different land use classes up to the third classification level according to Koellner et al. (2013) were extracted from official statistics provided by international organizations and then classified into the ILCD nomenclature (see Faragò et al. 2019 for further details about the mapping procedure). For both occupation and transformation to/from flows, the inventory and the CFs cover the following classes: forest, primary; forest, secondary; forest, extensive; forest, intensive; arable; arable, fallow; pasture/meadow; permanent crops; shrubland; wetlands; grassland; snow and ice; wetlands; bare area; urban.

Time series at country-scale resolution were used. The inventory for transformation flows was estimated as the difference between two consecutive years of occupation data, as proposed by Sala et al. (2014), by taking into account the 2005-2010 time span.

\subsubsection{Normalization factors}

The overall ILCD-based global NF for land use stands at $8.83 \mathrm{E}+14 \mathrm{~kg} \mathrm{C}$ deficit. The contribution analysis, performed considering both occupation- and transformation-related impacts and global default CFs (namely not country specific), highlights that India (18\%), Australia (6.19\%), China $(5.61 \%)$, USA (4.98\%), and Brazil (3.76\%) represent the countries which contribute the most to the overall impact. This is mainly linked to the wide occupation of forests, pastures, and meadows and their transformation into urban areas, which affects the availability of organic carbon in soil and, consequently, soil quality.

As the level of details according to the available statistics is rather low, it was not always possible to find a match between the $\mathrm{CF}$ and the inventory flows, thus potentially influencing the total impact. In fact, the inventory is covering mainly the level 1 of the land use type classification by Koellner et al. (2013), e.g., forest and pasture and only in few cases level 2 or level 3 (e.g., irrigated vs non-irrigated agricultural systems). Concerning countries coverage, complete unavailability 
occurs only in few cases and more than $95 \%$ of the world is covered for most of the flows taken into account, with the exception of some transformation flows and fallow land, whose data are mostly missing. Faragò et al. (2019) underline that the necessary extrapolation carried out in order to fill the data gaps related to transformation flows could reduce the robustness of the inventory.

An additional NF was calculated by means of the CFs of the EF reference package 3.0, which is using a soil quality index (EC 2017; Sala et al. 2019; De Laurentiis et al. 2019) expressed in terms of points ("pt") and based on the LANCA ${ }^{\circledR}$ model (Bos et al. 2016). The NF stands at $5.65 \mathrm{E}+15 \mathrm{pt}$ when country-specific CFs are used, and at $7.19 \mathrm{E}+15 \mathrm{pt}$ when using the global default factors only. The result obtained with this novel method is not comparable with the ILCD one presented above. As for the ILCD-based global $\mathrm{NF}$, the final contribution is due to both occupation and transformation-related impacts. On the occupation side, the most contributing impacts derive from the occupation of permanent pasture and meadows, secondary forest, and bare soil. Specifically, concerning transformations, the impacts are generally related to land use changes from forest to agriculture (permanent crops and arable land) and to urban areas. For example, Brazil is subject to a high impact due to the broad transformation of its forests into agricultural and other vegetative areas. Deforestation in Brazil and in other tropical areas is, indeed, a well-known problem (e.g., Keenan et al. 2015). On the contrary, China is among the main contributors to land transformation flows, in terms of "transformation to forest." In fact, from statistical data, it appears that China is subject to a transformation of shrublands and other vegetative lands to forests, mainly managed forests, likely following a process of reforestation both for biodiversity and timber harvesting due to the increased demand on the market (Viña et al. 2016).

\subsection{Water use}

\subsubsection{Global inventory}

Combinations of different data sources for the inventory and types of CFs led to the calculation of seven normalization factors for the water-use category (see ESM for a summary table of the tested combinations). Specifically, four normalization factors were calculated for the ILCD (i.e., a combination of two inventories and two sets of CFs), and three for the EF 3.0. For the ILCD, a first inventory was built on data from FAO database (FAO-Aquastat 2017) on freshwater withdrawals (i.e., from surface and groundwater, exception made for hydropower generation), complemented with extrapolations from Eurostat (2016) and OECD (2016). A second inventory was retrieved from the data on water withdrawal of the WaterGAP model (Müller Schmied et al. 2014), which includes both withdrawal and consumption data. The two inventories were characterized by using both average and country-specific CFs, thus resulting in the four abovementioned global normalization factors for ILCD. The mentioned average CF in ILCD represents the weighted average based on country water withdrawal, whereas the countryspecific CFs were retrieved as country-specific water scarcity ratios from Frischknecht et al. (2009) and its update (Frischknecht and Büsser Knöpfel 2013). In order to extend the coverage of the LCIA method including a higher number of countries, some approximations were made by adopting the geographic proximity and similar climatic conditions as main criteria for assigning a scarcity ratio to the countries not listed in Frischknecht and Büsser Knöpfel (2013) (see ESM for further details).

For the EF 3.0, a consumption-based inventory was retrieved from WaterGAP (Müller Schmied et al. 2014) and characterized with both average and country-specific CFs coming from the AWARE impact assessment model (UNEP 2016; Boulay et al. 2018). According to AWARE, which evaluates the impact in quantity of water deprived, the average $\mathrm{CF}$ is the weighted average based on country water consumption. For reason of completeness, a third normalization factor for EF 3.0 was calculated by characterizing the same consumption-based inventory using non-marginal CFs provided by Boulay et al. (2019). This was due to the fact that, as recognized by several authors (Huijbregts et al. 2011; Pfister and Bayer 2013) as well as recommended by UNEP (Verones et al. 2017), large-scale interventions are properly characterized by non-marginal CFs instead of the marginal ones, which are typically the default factors made available by model developers.

Concerning the year 2010 for withdrawal data, WaterGAP is the most complete database, whereas the other complemented inventory presents missing values for many countries, some of them with a potentially significant role in the water use category (e.g., China). For this reason, values referred to other years and coming from the same sources (specifically 2008-2014 time span from FAOSTAT) were used to fill the gaps, in line with the hierarchical approach explained in "Section 2."

Concerning the WaterGAP consumption inventory, almost all the countries in the world (212 countries out of 215) were associated with an inventory value for 2010 and characterized by means of country-specific CFs.

\subsubsection{Normalization factors}

A set of seven normalization factors were calculated: four for ILCD and three for the EF 3.0. For ILCD, the calculated normalization factors are (a) $5.01 \mathrm{E}+11 \mathrm{~m}^{3}$ water eq, based on data from FAO (FAO-Aquastat 2017) complemented with Eurostat (2016) and OECD (2016) multiplied by global average $\mathrm{CFs}$; (b) $4.80 \mathrm{E}+13 \mathrm{~m}^{3}$ water eq, based on data from FAO 
(FAO-Aquastat 2017) complemented with Eurostat (2016) and OECD (2016) multiplied by country-specific CFs; (c) $7.10 \mathrm{E}+11 \mathrm{~m}^{3}$ water eq, built on WaterGAP-based withdrawal inventory multiplied by global average CFs; and (d) 7.67E+ $13 \mathrm{~m}^{3}$ water eq, built on WaterGAP-based withdrawal inventory by country-specific CFs. The recommended global NF is (d) $7.67 \mathrm{E}+13 \mathrm{~m}^{3}$ water eq, for which the most contributing countries are India (45\%), China (11\%), and Pakistan (11\%). For EF 3.0, the calculated normalization factors are (e) 7.89E+ $13 \mathrm{~m}^{3}$ water eq of deprived water, derived from WaterGAPbased consumption inventory multiplied by global average CFs; (f) $7.91 \mathrm{E}+13 \mathrm{~m}^{3}$ water eq of deprived water, derived from WaterGAP-based consumption inventory multiplied by country-specific CFs; and (g) $1.68 \mathrm{E}+13 \mathrm{~m}^{3}$ water eq of deprived water, derived from WaterGAP-based consumption inventory multiplied by country-specific non marginal CFs. The global NF to be used is (f) $7.91 \mathrm{E}+13 \mathrm{~m}^{3}$ water eq of deprived water, whose highest contribution is given by China (16\%), India (13\%), and Pakistan (8\%).

While options (e) and (f) gave similar results, the use of nonmarginal CFs led to a significantly lower NF compared, reflecting the different nature of the CFs. Moreover, the list of the main contributors changes, namely China and India show lower contribution to the overall impact (13\% and $10 \%$ respectively) and Egypt now is a contributor (9\%), closely followed by Pakistan (8\%). These aspects suggest that using marginal CFs for characterizing large-scale inventories may lead to significant overestimations of NF. In fact, the CFs based on the AWARE model (Boulay et al. 2018) are recommended by UNEP (2016) and suggested to be used by the EF 3.0 (Sala et al. 2019; Fazio et al. 2018b) for characterizing marginal consumption only, whereas the use of non-marginal CFs is appropriate when assessing large-scale interventions such as global water consumption.

Generally, watershed-scale impact assessment is adopted for evaluating and quantifying how water use contributes to the water scarcity problem. However, for what concerns the spatial scale of the recommended normalization factor, especially in the EF context, the country-specific scale is used. This, which may be seen as a limitation in the quantification of the environmental impact, is mainly dictated by applicability reasons, especially in the Environmental Footprint context. In fact, the impact assessment method AWARE (UNEP, 2016; Boulay et al. 2018), which is included in the EF 3.0 method, takes into account few resolution levels, both temporal and spatial (e.g., month, watershed, and continental/region). However, only the country scale is to be used in the common LCA practice (Fazio et al. 2018b).

\subsection{Resources use}

\subsubsection{Global inventory}

Two groups of data were retrieved, namely (i) minerals and metals and (ii) energy carriers (i.e., fossils and uranium).
Both the normalization factors, i.e., ILCD 2011 and EF 3.0, are built on the same model which assess the abiotic resource depletion (ADP) (van Oers et al. 2002 and its update version van Oers and Guinée 2016). However, in the EF update, the "ultimate reserve" approach is taken whereas the "reserve base" is the one adopted in ILCD (EC-JRC 2011, 2012).

The inventory related to minerals and metals was built by relying on USGS statistics (USGS 2011a, b), to which a specific approach was applied, involving conversion from compounds to elements for arsenic, chromium, phosphorus, potassium, and rare earths. In fact, the data retrieved for these flows were representative for the oxide compound of the element (e.g., arsenic trioxide, chromite, potash) which is effectively mined, and not on the metal content itself as generally provided by mine production data. Therefore, the amount of the elements themselves was extrapolated by using the molecular weight of the oxide compound and the atomic weight of the element. For several elements, namely antimony, gold, platinum, silver, and tellurium, statistics were complemented with information from the British Geological Survey (BGS 2017) according to the major completeness of the inventory in terms of higher coverage in emitting countries with respect to USGS. Extrapolations were applied to a reduced number of cases, namely six out of 66 , and the extrapolated fraction $(\mathrm{kg})$ out of the total amount of minerals and metals is very low $(1 \%)$. The inventory of minerals and metals covers 66 elementary flows out of 73 for which a CF was available in ILCD, positively contributing to the completeness of the NF.

For what concerns the accounting of fossils within the global inventory, two different data sources were used, namely the International Energy Agency (IEA 2014) for peat, brown and hard coal, natural gas, and crude oil and the World Nuclear Association website (WNA 2016b) for uranium mining. However, data for both fossils and uranium production refer to the year 2013 and were retrieved as total mass. The inventory based on fossils presents a full coverage (i.e., 100\%) of the ILCD elementary flows.

\subsubsection{Normalization factors}

The calculated NF for ILCD stands at 3.74E+09 $\mathrm{kg}$ Sb equivalents, and more than $99 \%$ is due to the contribution of minerals and metals, thus proving that when metal and fossil are combined, there could be a relevant underestimation of the depletion of energy reserves at the global scale. The largest contributors to the characterized result for this group (i.e., 3.73E+09 $\mathrm{kg} \mathrm{Sb}$ equivalents) are germanium (61\%) and indium (ca. 10\%) that together with silver, antimony, lithium, strontium, and lead contribute to $90 \%$ of the impact derived from mineral and metals. However, it should be taken into account that (i) data on reserve for germanium and indium are scarce and this is affecting the CFs provided in 
Table 4 Overview of the relative environmental impacts of the European system compared to the world and expressed as a percentage. The share is reported, for each impact category according to the calculations from (i) this study; (ii) the NFs calculated in the Prosuite Project, Laurent et al. (2013); and (iii) the NFs of Sleeswijk et al. (2008)

\begin{tabular}{|c|c|c|c|c|}
\hline \multirow[b]{2}{*}{ ILCD impact category } & \multirow[b]{2}{*}{$\begin{array}{l}\text { Unit according } \\
\text { to ILCD* }\end{array}$} & \multicolumn{3}{|c|}{ EU/global NFs ratio (\%) } \\
\hline & & $\begin{array}{l}\text { As in this study } \\
\text { (ILCD v.1.010) }^{\mathrm{a}}\end{array}$ & $\begin{array}{l}\text { As in PROSUITE } \\
\text { (Laurent et al. 2013) }^{\text {b }}\end{array}$ & $\begin{array}{l}\text { As in Sleeswijk } \\
\text { et al. }(2008)^{\mathrm{c}}\end{array}$ \\
\hline Climate change & $\mathrm{kg} \mathrm{CO}_{2}$ eq & 9 & 8 & 12 \\
\hline Ozone depletion & kg CFC-11 eq & 3 & 4 & 3 \\
\hline Human toxicity, cancer & CTUh & 6 & 5 & 10 \\
\hline Human toxicity, non-cancer & CTUh & 5 & 4 & 10 \\
\hline Particulate matter & $\mathrm{kg} \mathrm{PM}_{2.5}$ eq & $2^{\mathrm{d}}$ & 10 & 8 \\
\hline Ionizing radiations & $\mathrm{kBq} U-235 \mathrm{eq}$ & $61^{\mathrm{e}}$ & 6 & 36 \\
\hline Photochemical ozone formation & $\mathrm{kg}$ NMVOC eq & 6 & 4 & 8 \\
\hline Acidification & $\mathrm{mol} \mathrm{H}^{+}$eq & 6 & 7 & 8 \\
\hline Eutrophication, terrestrial & mol $\mathrm{N}$ eq & 7 & 11 & n.a. \\
\hline Eutrophication, freshwater & $\mathrm{kg} P$ eq & 7 & 17 & 9 \\
\hline Eutrophication, marine & $\mathrm{kg} \mathrm{N}$ eq & 6 & 13 & 10 \\
\hline Land use & $\mathrm{kg} \mathrm{C}$ deficit & 4 & 2 & 6 \\
\hline Ecotoxicity freshwater & CTUe & 8 & $21^{\mathrm{f}}$ & 20 \\
\hline Water depletion (water use in EF) & $\mathrm{m}^{3}$ water eq & $<1$ & 20 & n.a. \\
\hline Resource depletion (resource use in EF) & $\mathrm{kg} \mathrm{Sb}$ eq & 1 & 2 & n.a. \\
\hline
\end{tabular}

*The units of measurements in the other references (i.e., Sleeswijk et al. 2008; Laurent et al. 2013) may be different from those recommended in ILCD. However, this aspect does not influence the result, since the ratio is dimensionless

${ }^{\text {a }}$ EU27 NF from Sala et al. (2015), based on territorial perspective; global NFs from this study, calculated according to ILCD v.1.010 (EC-JRC 2011). EU27 represents the administrative composition of the European Union in 2010

${ }^{\mathrm{b}}$ EU27 NF from Sala et al. (2015), based on territorial perspective; global NFs from Prosuite (Laurent et al. 2013)

${ }^{\mathrm{c}}$ EU25+3 NF and global NF from Sleeswijk et al. (2008); EU25+3 represents the administrative composition of the European Union in 2006 plus Iceland, Norway, and Switzerland

${ }^{\mathrm{d}}$ This ratio becomes $4 \%$ if considering the alternative Global NF for particulate matter, namely the one based on the unspecified height of emission (as the underpinning calculation of EU NFs does)

${ }^{\mathrm{e}}$ This value is based on the updated calculation of the EU27 NF for ionizing radiations (5.81E+11 kBq U-235 eq), according to the principles and data sources underpinning the global NF described in this study, in particular by accounting for the specific radionuclides discharges and electricity generated per nuclear reactor type

${ }^{\mathrm{f}}$ The ratio is the one resulting from a comparison of EU 27/global as in Cucurachi et al. (2014) adopted in Prosuite, selecting the $\mathrm{CO}_{2}$-based extrapolation

the impact model, leading to an overestimation of their relevance and (ii) specific extrapolations were necessarily adopted for the of resources, as explained in "Section 2.2," inevitably adding uncertainty to the results. On the other hand, uranium drives the overall impact for energy carriers contributing up to $78 \%$ of the total value for this group (i.e., $1.5 \mathrm{E}+07 \mathrm{~kg}$ Sb equivalents).

The NF for the EF 3.0 is reported as two separated values: one for minerals and metals and one for fossils plus uranium (4.39E+08 $\mathrm{kg} \mathrm{Sb}$ eq and 4.48E+14 MJ respectively). The EF 3.0 impact assessment model for fossil and uranium depletion provides characterization factors expressed per units of thermic energy (MJ). Therefore, the conversion to energy equivalents (thermic MJ) was performed by using their average thermic energy content in the case of fossil fuels and by considering a specific reference process (i.e., an average water reactor) for heat production stemming from uranium fuel
(EC-JRC 2012). The contribution of flows is changing due to the use of the ultimate reserve approach, resulting in $37 \%$ of antimony, $32 \%$ of gold, and $6 \%$ of silver for the category resource use mineral and metals, whereas is $38 \%$ of oil and $24 \%$ of natural gas for the category resource use, fossil.

Even if the calculation for the current ILCD was split as well for the sake of comparison (in ESM), the values are not fully comparable because of the difference in the approach in the ADP calculation (i.e., reserve base vs. ultimate reserve).

\subsection{Comparison of European over global normalization factors}

As previously done by Sleeswijk et al. (2008), European and global normalization factors were compared to support the 
interpretation of the results. The share of impact due to emissions and resource extraction occurring within EU27 with respect to the impacts occurring at the global scale are reported in Table 4, considering different references, namely

- The ratio between the NFs for EU27 (Sala et al. 2015) and the global NFs, both calculated by means of ILCD. Both inventories refer to the year 2010 .

- The ratio between the NFs for EU27 (Sala et al. 2015) and Prosuite NFs for the year 2010 (Laurent et al. 2013).

- The ratio between EU25+3 and the global NFs as reported by Sleeswijk et al. (2008) for the year 2000

The global NFs proposed in the Prosuite project (Laurent et al. 2013) are built on the same temporal scale and models of the global NFs that we propose, while in Sleeswijk et al. (2008), the reference system is different both from the temporal (i.e., 2000 vs. 2010) and the spatial point of view (i.e., EU25+3 vs. EU27).

The ILCD-related EU/global ratios stemming from the calculations presented in this paper show that EU27 figures (Sala et al. 2015) do not generally exceed $10 \%$ of world impacts, with the exception of ionizing radiation. That percentage roughly represents the share of the EU over the world population and can be used as a benchmark to assess whether scaled by population size; the EU is directly impacting more or less than an average world citizen. A value higher than $10 \%$ means that in the EU, a certain impact is higher than in comparison to the world average, scaled by population, and vice versa for values $<10 \%$. Such differences can be explained by (i) the characteristic of the phenomenon investigated (e.g., distribution of natural resources, use of a certain technology in Europe), (ii) a difference in accounting or characterization between the two sets of normalization factors, or (iii) a systematic error underpinning one of the two normalization sets. The most significant European contribution is registered for the category ionizing radiations $(61 \%)$, distantly followed by climate change (9\%). According to the results in "Section 3.5," carbon-14 represents the most important flow in terms of impact on a global scale for the category ionizing radiations. Considering this radionuclide only, it is possible to observe that the emissions of carbon-14 registered at global level mainly come from nuclear power plants installed only in EU and operating for electricity production (see $100 \%$ values in Table 5). These, together with the other active reactors contribute to $58 \%$ of carbon- 14 world emissions. Furthermore, another important source of carbon-14 in Europe is the spent-fuel reprocessing activities, which account for roughly $17 \%$ of the total emissions. By combining these sources, it is possible to explain why the EU contribution is so high in comparison to the rest of the world.

On the other hand, the lowest value is associated with the water use impact category $(<1 \%)$. As reported in "Section 3.12," most of the impacts are due to water withdrawal in extra-EU countries, namely India, China, and Pakistan, with EU27 only covering 8\% of global water withdrawal at inventory level. However, this ratio embeds the difference in the characterization between the two sets of normalization factors. To overcome it, we calculated the ratio between the EU27 NF from Sala et al. (2015) and a global NF by means of an average $\mathrm{CF}$, as the calculation of the EU27 NF does. The novel ratio stands at $8 \%$, which reflects the European share of water withdrawal on a global scale. Even the EU27 fraction for resource use is considerably low, due to the relatively limited extraction activities taking place within EU27 territory (Sala et al. 2015) compared to global scale (e.g., Europe is extracting only $1.6 \%$ of the global extraction of crude oil).

Table 5 Global and EU emissions ( $\mathrm{kBq}$ ) of carbon-14 in 2010. The contribution of EU operating nuclear power plants to the electricity generation is reported herein. Data source: UNSCEAR (2017a)

\begin{tabular}{|c|c|c|c|c|c|}
\hline Source of C-14 emission & $\begin{array}{l}\text { Global electricity } \\
\text { generated from nuclear } \\
\text { power plants }(\mathrm{GW} \mathrm{a})\end{array}$ & $\begin{array}{l}\text { Europe share of electricity } \\
\text { produced with the specific } \\
\text { technology }(\%)\end{array}$ & $\begin{array}{l}\mathrm{C}-14 \text { discharges } \\
\text { to air }(\mathrm{kBq} / \mathrm{GW} \text { a) }\end{array}$ & $\begin{array}{l}\mathrm{C}-14 \text { emissions- } \\
\text { EU scale }(\mathrm{kBq})\end{array}$ & $\begin{array}{l}\text { C-14 emissions- } \\
\text { global scale }(\mathrm{kBq})\end{array}$ \\
\hline PWR & 204.88 & 50 & $8.30 \mathrm{E}+07$ & $8.51 \mathrm{E}+09$ & $1.70 \mathrm{E}+10$ \\
\hline BWR & 63.72 & 19 & $1.30 \mathrm{E}+08$ & $1.58 \mathrm{E}+09$ & $8.28 \mathrm{E}+09$ \\
\hline HWR & 17.09 & 7 & $6.00 \mathrm{E}+08$ & $7.32 \mathrm{E}+08$ & $1.03 \mathrm{E}+10$ \\
\hline LWGR & 8.15 & 100 & $1.30 \mathrm{E}+09$ & $1.06 \mathrm{E}+10$ & $1.06 \mathrm{E}+10$ \\
\hline AGR & 5.01 & 100 & $1.40 \mathrm{E}+09$ & $7.01 \mathrm{E}+09$ & $7.01 \mathrm{E}+09$ \\
\hline GCR & 0.93 & 100 & $5.50 \mathrm{E}+09$ & $5.12 \mathrm{E}+09$ & $5.12 \mathrm{E}+09$ \\
\hline FBR & 0.42 & 100 & $1.20 \mathrm{E}+08$ & $5.04 \mathrm{E}+07$ & $5.04 \mathrm{E}+07$ \\
\hline \multicolumn{4}{|c|}{ Spent-fuel reprocessing ( $21 \%$ reprocessed in EU) } & $1.63 \mathrm{E}+10$ & $7.84 \mathrm{E}+10$ \\
\hline \multicolumn{4}{|l|}{ Total } & $4.99 \mathrm{E}+10$ & $7.84 \mathrm{E}+10$ \\
\hline
\end{tabular}

$P W R$, pressurized water reactor; $B W R$, boiled water reactor; $H W R$, $\mathrm{H}$ water reactor; $L W G R$, light water gas-cooled reactor; $A G R$, advanced gas-cooled reactor; $G C R$, gas-cooled reactor; $F B R$, fast breeder reactor 


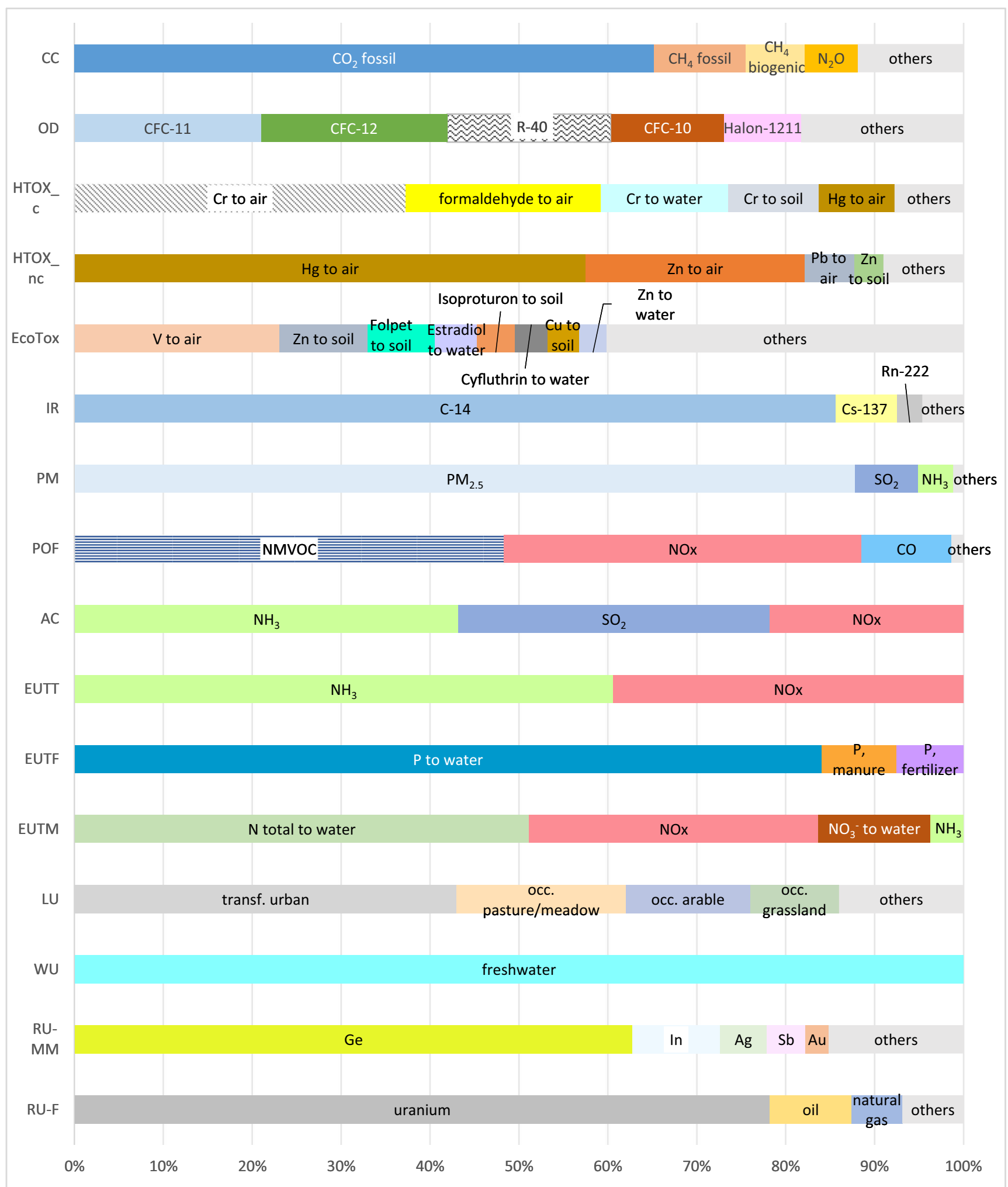

Fig. 1 Overview of the main contributing substances, in terms of percentage of the overall impact of different impact categories, characterized with ILCD CFs, for climate change (CC); ozone depletion (OD); human toxicity-cancer effects (HTOX c) and non-cancer effects (HTOX_nc); ecotoxicity (EcoTOX); ionizing radiation (IR); particulate matter (PM); photochemical ozone formation (POF); acidification (AC); eutrophication terrestrial (EUTT), freshwater (EUTF) and marine (EUTM); resource use both minerals and metals (RU-MM) and fossils (RU-F) 
For what concerns particulate matter, it is worth noticing that the calculation of the global NF was done accounting for the specification of the emission height, while in the EU27 $\mathrm{NF}$, this does not occur. By considering the global NF calculated without accounting for height specification (thus making a comparison between values obtained on the same basis), the ratio EU/global becomes closer to $4 \%$, comparable with $6 \%$ in photochemical ozone formation. It is reasonable that these values are below $10 \%$ because in the developing countries, especially in BRIC countries, there are many sources of such emissions (see ESM).

Regarding acidification- and eutrophication-related impact categories, whose inventory behind is almost the same to some extent, the ratio EU/global can be explained by the fact that the share of agriculture per person (in terms of total land used for agricultural purposes) is higher in the rest of the world than in EU (World bank 2017).

The ratios derived from Laurent et al. (2013) are generally close to our calculations, namely with the majority of EU27 share of impact around or below $10 \%$ with respect to the global impact. However, for some categories, the European share of impact in Laurent et al. (2013) highly exceeds this value, particularly in the case of ecotoxicity freshwater where $21 \%$ of the global impact is given by the EU27 contribution. This is linked to the fact that the global NF for the freshwater ecotoxicity category in Laurent et al. (2013) is represented by the $\mathrm{CO}_{2}$ emission-based factor as calculated in Cucurachi et al. (2014), which is indeed significantly lower than the $\mathrm{Hg}$ emission-based value that we used with further extrapolations from Cucurachi et al. (2014).

In spite of the difference in the reference system with previous exercises, in several cases, the resulting ratios from Sleeswijk et al. (2008) do not appear to differ particularly compared to the others calculated ratios, namely with EU values below $10 \%$ of the world-related impact. However, for ionizing radiation, the EU27 impact represents the $36 \%$ of the overall global impact. This is likely due to the fact that, according to the authors, the normalization factor for the global scale was estimated by using the European system as representative of the global situation, thus leading to a potential misleading estimation of the final global reference (as for the relative share of EU compared to global emission of ionizing as for Table 5).

It is important to note that such results are expected to change significantly if a consumption-based perspective is adopted instead of a territorial one, i.e., by accounting for direct as well as indirect impacts associated with consumption patterns occurring within the EU27. This may lead to a larger share of impacts due to EU27 final consumption, which includes the embodied emissions happening elsewhere (Sala et al. 2016).

Figure 1 reports a summary of the contribution analysis for a number of selected impact category according to ILCD characterization method (EC-JRC 2011, 2012). The contribution according to the EF method is reported in ESM. The figure shows to what extent the inventoried substances contribute to the global normalization factor for each selected category. The contribution to the impact is expressed as a percentage of the overall impact at the global level for each impact category included in the analysis, addressing explicitly those substances that contribute around $85 \%$ to the overall impact.

As for the contribution analysis discussed in Sala et al. (2015) for the EU27 normalization factor, in the majority of the impact categories, only a few elementary flows contribute the most to the overall impact, and for all impact categories, a single flow drives the impact, by contributing at least $21 \%$ (e.g., CFC-11 for ozone depletion) up to about $88 \%$ (e.g., $\mathrm{PM}_{2.5}$ in particulate matter) to the overall impact. The reasons underpinning this aspect are extensively discussed in Sala et al. (2015) and are reasonable also for the global normalization factors, in particular for climate change, ionizing radiation, and human toxicity-related impacts, since the underpinning inventories are generally based on the same set of rules and the CFs adopted in the characterization step come from the same source, i.e., ILCD (EC-JRC 2012). For the other categories, the results of the contribution analysis at EU27 and global level are generally similar, with a high share of impacts deriving from the energy sector (e.g., $\mathrm{CO}_{2}, \mathrm{PM}_{2.5}$, and $\mathrm{NO}_{\mathrm{x}}$ ) just to name an example. However, the contribution to the global impact due to resource depletion and ecotoxicity shows some differences compared to the EU27 impacts. In fact, the extraction and use of germanium, followed by indium, represent the highest contributors to resource depletion, while in the European Union, almost $70 \%$ of the overall impact is given by strontium and silver. This is due to the differences in the level of extraction in the EU and globally. Concerning global impacts of ecotoxicity, the highest impact is due to the emission of vanadium to air (23\%), which does not occur in the EU27 NF. This substance is emitted in high amount during the processes of coal combustion and bitumen production (Schlesinger et al. 2017).

For what concerns land use, we carried out a contribution analysis at flow level by using global default CFs, in order to be compliant with EU27 NFs from Sala et al. (2015) and allow for a comparison. The results show that at a global level, most of the impact is related to urban transformation (43\%), followed by "permanent meadows and pastures" (19\%). "Grassland" and "arable" flows have a modest relevance (14\% and $10 \%$, respectively). Most of the transformation at inventory level occurred at the global scale is from forests to arable lands or to urban areas. The flow "transformation to urban" represents the most relevant one also from the impact assessment point of view; in fact, its impact is about two orders of magnitude higher than the transformation to agriculturally related flows, e.g., "to permanent crops" and "to arable." Generally, impacts due to agricultural land occupation (including permanent crops, arable land with and without 
fallow, permanent meadows, and pastures) represent $30 \%$ out of the overall global impact due to land occupation, and urban occupation stands at $1 \%$. This is in line with the global NF result, where the sum of "permanent meadows and pastures" and "arable" related contributions is about $29 \%$, but not consistent with EU27 land occupation-related impacts. In this case, agriculture and urban activities represent a major source of impact.

Regarding the contribution to water use, very high contribution to the overall impact is related to India (45\%), distantly followed by China and Pakistan (both 11\%), which also represent those countries with high level of water withdrawal at inventory.

\section{Conclusion and outlook}

In this work, a set of normalization factors for the year 2010 were estimated with the aim of assessing environmental impacts at the global scale. The novelty of the NF sets presented in this study is associated with their consistency with both the ILCD and EF methods, thus opening the possibility to be used in the PEF/OEF contexts (Zampori \& Pant 2019a, b). Furthermore, compared to previous studies, this is the first time that several data sources and methodological options are systematically assessed and compared. In ESM, the different data sources and assumptions are extensively reported, as the basis for future improvements and to be used for sensitivity analysis of the results. Despite the attempts made for increasing coverage and robustness of the normalization factors (i.e., by adopting extrapolation strategies), current estimations still show intrinsic limitations. Therefore, the use of such results in LCIA as well as the consequent interpretation of normalized results has to be performed with care, especially for those NFs showing low levels of robustness. As previously suggested by Sala et al. (2015) and Benini and Sala (2016) for the EU27 normalization factors, the improvements should focus predominantly on the following aspects: completeness of the inventory; methodological choices adopted; completeness and robustness of the impact assessment.

\subsection{Completeness of the inventory}

More robust inventories for the impact categories should be set, focusing on their completeness in terms of the coverage of elementary flows and representativeness of the most impacting substances, for each impact category. Global inventories of emissions and resource use, as available in the literature, are generally affected by the limited availability of recent data, due, for example, to missing submission by parties as in the case of officially reported data based on accepted methods and models. In our study, we evaluated the option of partially overcoming this issue by building inventories based on different reliable data sources; however, data sources may lack a certain level of harmonization among the approaches used for obtaining emission and resource use data. Therefore, in order to complement the current inventories underpinning the calculation of the global normalization references, a systematic collection of more detailed and precise data associated to the global emission profile and resource use is still needed, ensuring consistency of assumptions and extrapolations. Moreover, there is a need for improving the geographical coverage of inventories, especially for those categories whose impacts are spatially dependent (e.g., water use or land use). The availability of and the easy access to spatially explicit data sources for those impact categories, with data aggregated at least at the national level, would result in a better and more accurate accounting of impacts.

\subsection{Methodological choices}

As reported in Benini and Sala (2016), several methodological choices, such as the classification of elementary flows, the use of derived average CFs (as in the case of ozone depletion and water use), or the presence of substance groups (e.g., NMVOC) in the inventory, represent significant sources of uncertainty issues. For instance, for what concerns the classification of elementary flows, the use of synonyms available in the literature for identifying the same substance may generate inconsistencies in the final flow mapping and in the identification of the corresponding CFs. Therefore, a univocal nomenclature system should be defined, at least at the level of LCA inventories. Moreover, the lack of CFs in the applied LCIA methods, or the estimation of average CFs, for several substances which are instead available in the statistics would prevent or mislead the contribution to better assess the impacts. Additionally, in this work, emission-related figures have been collected for a defined year, namely 2010, taken as reference. However, to deal with delayed emissions, as mentioned in Sala et al. (2015), it could be worthy to analyze the impact trends throughout a temporal series.

\subsection{Impact assessment}

Global normalization factors in this paper were calculated by using the recommended ILCD method (EC-JRC 2011, 2012) and the EF method (Zampori \& Pant 2019a, b; Fazio et al. 2018b; Sala et al. 2019). For both methods, the results have been classified in terms of robustness levels, to provide guidance to the use of normalization factors by LCA practitioners.

Regionalization at the impact assessment level through the use of country-specific CFs instead of global default or average ones might lead to differences in results. For instance, in the calculation of global NF for water use impact category by 
means of the EF reference package 3.0, the obtained results are comparable within the same order of magnitude, whereas for the ILCD calculation, regionalization carries a difference of two orders of magnitude. This kind of reasoning could be applied also when very detailed CFs are available for certain types of inventory data beyond the geographic scale. For instance, the underpinning model for water use (UNEP 2016; Boulay et al. 2018) provides CFs that can be specifically associated to the consumption of water due to irrigation practices: choosing specific CFs might affect the impact due to the agricultural sector and, consequently, the final NF. Another important aspect to be taken into consideration in the LCIA phase relates to the use of marginal or non-marginal average CFs. This becomes significant, especially when evaluating pressures, e.g., on water use, whose effects strongly depend on the background inventory or on the already occurring interventions (according to Boulay et al. 2019). As revealed in our calculation, when dealing with large-scale interventions, as for global water consumption, a marginal approach, compared to the use of average CFs, may overestimate the resulting impact.

\subsection{Consistency between inventory, impact assessment, and normalization}

The calculation of a normalization reference, which could be used in the common LCA practice, needs to take into consideration some aspects for the sake of consistency. In fact, the choice of the level of detail for both the inventory and the CFs underpinning the calculation of the global NFs should be done while ensuring consistency between the calculated normalization factors themselves and the LCA results that are to be normalized, namely both the inventory for the product/ service life cycle assessment and the characterization factors adopted in the common LCA practice. For instance, when a model can be applied at the country level, the inventory for normalization is built on a country level basis. However, the average available background dataset used for building LCA inventories may miss the geographical details, e.g., land use inventories in secondary datasets usually do not report country specification. On the other hand, as for the case of acidification indicator, country-specific inventory data can be retrieved, whereas the model provides CF's for EU countries only, without accounting for the rest of the world.

Additionally, an open question concerns the definition of the system boundaries between technosphere and ecosphere when modelling certain impacts that leads to differences in the way the LCI of some impact categories is combined with LCIA. In fact, the question around drawing the borders between technosphere and ecosphere in a consistent and meaningful way is a gray area in LCA that need to be solved in order to improve the characterization. Particularly, the system boundary definition is of relevance for processes and emissions/extractions in the agricultural sector and the impact categories associated with this (e.g., eutrophication, acidification, ecotoxicity). In order to be consistent, the same system boundary should be used in the inventory of the total emissions and extractions underpinning the calculation of normalization factors, in the inventory of process data for the product/ service life cycle assessment, and, finally, in the impact assessment model. By choosing the characterization factor sets (in this specific case ILCD and EF), the environmental processes and the emissions are to be defined accordingly. In fact, it is crucial to clearly identify which flows are the inputs into the model, namely the application of the nutrient to soil or the surplus (i.e., application minus uptake) just to mention an example. Therefore, in order to ensure a better accounting of impacts and allowing the reliable use of normalization factors, it becomes fundamental to solve such consistency issues.

Acknowledgments The authors would like to thank Alexis Laurent and Maria Faragò for their contribution to the land use inventory; WaterGAP for providing data for the water use inventory; and Rana Pant, European Commission JRC, for his time and efforts in discussing key aspects of this paper.

Funding information The present study was financially supported by the Administrative Arrangements no. 07.0307/ENV/2013/SI2.668694/A1 and no. 07.0201/2015/704456/SER/ENV.A1 between the European Commission Directorate General Environment and the Joint Research Centre.

\section{Compliance with ethical standards}

Conflict of interest The authors declare that they have no conflict of interest.

Open Access This article is distributed under the terms of the Creative Commons Attribution 4.0 International License (http:// creativecommons.org/licenses/by/4.0/), which permits unrestricted use, distribution, and reproduction in any medium, provided you give appropriate credit to the original author(s) and the source, provide a link to the Creative Commons license, and indicate if changes were made.

\section{References}

Aus der Beek T, Flörke M, Lapola DM, Schaldach R (2010) Modelling historical and current irrigation water demand on the continental scale: Europe. Adv Geosci 27:79-85

Benini L, Sala S (2016) Integrated assessment of environmental impact of Europe in 2010: uncertainty and sensitivity of the normalisation factors to methodological assumptions. Int J Life Cycle Assess 21(2):224-236

BGS (British Geological Survey) (2017) World mineral statistics data. Available at: https://www.bgs.ac.uk/mineralsuk/statistics/wms.cfc? method=searchWMS. Accessed October 2017

Bos U, Horn R, Beck T, Lindner JP, Fischer M (2016) LANCA® Characterisation Factors for Life Cycle Impact Assessment, Version 2.0, 978-3-8396-0953-8 Fraunhofer Verlag, Stuttgart 
Boulay AM, Bare J, Benini L, Berger M, Lathuillière MJ, Manzardo A, Margni M, Motoshita M, Núñez M, Pastor AV, Ridoutt B, Oki T, Worbe S, Pfister S (2018) The WULCA consensus characterization model for water scarcity footprints: assessing impacts of water consumption based on available water remaining (AWARE). Int J Life Cycle Assess 23(2):368-378

Boulay AM, Benini L, Sala S (2019) Non-marginal impact assessment in life cycle assessment and application to the AWARE water scarcity method. Submitted to the Int J Life Cycle Assess

Bouwman L, Goldewijk KK, Van Der Hoek KW, Beusen AH, Van Vuuren DP, Willems J, Rufino M, Stehfest E (2013) Exploring global changes in nitrogen and phosphorus cycles in agriculture induced by livestock production over the 1900-2050 period. Proc Natl Acad Sci 110(52):20882-20887

Cheng H, Zhou T, Li Q, Lu L, Lin C (2014a) Anthropogenic chromium emissions in China from 1990 to 2009. PLoS One 9(2):e87753

Cheng K, Tian HZ, Zhao D, Lu L, Wang Y, Chen J, Liu XG, Jia WX, Huang Z (2014b) Atmospheric emission inventory of cadmium from anthropogenic sources. Int J Environ Sci Technol 11(3):605616

Cucurachi S, Sala S, Laurent A, Heijungs R (2014) Building and characterizing regional and global emission inventories of toxic pollutants. Environ Sci Technol 48(10):5674-5682

Cucurachi S, Seager TP, Prado V (2017) Normalization in comparative life cycle assessment to support environmental decision making. J Ind Ecol 21(2):242-243

De Laurentiis V, Secchi M, Bos U, Horn R, Laurent A, Sala S (2019) Soil quality index: exploring options for a comprehensive assessment of land use impacts in LCA. J Clean Prod 215:63-74. https://doi.org/ 10.1016/j.jclepro.2018.12.238

Dreicer M, Tort V, Manen P. (1995). ExternE, xternalities of Energy, Vol. 5. Nuclear, Centre d'étude Sur l'Evaluation de la Protection dans le domaine Nucléaire (CEPN), edited by the European Commission DGXII, Science, Research and Development JOULE, Luxembourg, 1995

EC (2013a). Communication from the Commission to the European Parliament and the Council - Building the Single Market for Green Products - Facilitating better information on the environmental performance of products and organisations. COM(2013)196

EC (2013b). Recommendation 2013/179/EU on the use of common methods to measure and communicate the life cycle environmental performance of products and organisations, Annex III, OJ L 124, 4.5.2013, p. $1-210$

EC (2017) PEFCR Guidance document - Guidance for the development of Product Environmental Footprint Category Rules (PEFCRs), version 6.3, December 2017. Available at http://ec.europa.eu/ environment/eussd/smgp/pdf/PEFCR_guidance_v6.3.pdf (Accessed November 2018). CFs package and supplementary info available at: http://eplca.jrc.ec.europa.eu/LCDN/developerEF.xhtml

EC-JRC (2011) Recommendations based on existing environmental impact assessment models and factors for life cycle assessment in European context. Luxembourg: Publications Office of the European Union. EUR24571EN

EC-JRC (2012) Characterisation factors of the ILCD Recommended Life Cycle Impact Assessment methods. Luxembourg: Publications Office of the European Union. EUR 25167EN

EC-JRC (2017) Environmental Footprint dataset "Crude oil mix technology mix of conventional (primary, secondary and tertiary production) and unconventional production (oil sands, in-situ) consumption mix, to consumer"

EC-JRC \& PBL (2011) Emission Database for Global Atmospheric Research (EDGAR). Global Emissions EDGAR v. 4.2. http:// edgar.jrc.ec.europa.eu/overview.php?v=42. Accessed October 2016

EC-JRC \& PBL (2013) Emission Database for Global Atmospheric Research (EDGAR), released version 4.2 FT2010. http://edgar.jrc. ec.europa.eu/overview.php?v=42FT2010. Accessed October 2016
EC-JRC \& PBL (2016) Emission Database for Global Atmospheric Research (EDGAR), released version 4.3.1. http://edgar.jrc.ec. europa.eu/overview.php?v=431. Accessed October 2016

EC-JRC \& PBL (2018) Global speciated NMVOC Emissions: EDGAR v4.3.2 VOC spec (January 2017). Available from: http://edgar.jrc. ec.europa.eu/overview.php?v=432_VOC_spec. Accessed November 2018

European Nuclear Society (ENS) (2016) Reprocessing plants, worldwide. https://www.euronuclear.org/info/encyclopedia/r/ reprocessing-plants-ww.htm. Accessed February 2017

Eurostat (2016) Annual freshwater abstraction by source and sector [env_wat_abs]. http://ec.europa.eu/eurostat/web/productsdatasets/-/env wat abs. Accessed November 2016

Fahey DW, Hegglin ML (2011) Twenty questions and answers about the ozone layer: 2010 update, in scientific assessment of ozone depletion: 2010, global ozone research and monitoring project - report no. $52,516 \mathrm{pp}$, WMO, Geneva, Switzerland

Fantke P, Evans J, Hodas N, Apte J, Jantunen M, Jolliet O, Mckone TE (2016) Health impacts of fine particulate matter. In: Frischknecht R, Jolliet O (eds) Global guidance for life cycle impact assessment indicators: Vol 1. UNEP/SETAC Life Cycle Initiative, Paris, pp 76-99. www.lifecycleinitiative.org/applying-lca/lcia-cf/. Accessed January 2017

FAO (2010). Global forest resources assessment 2010. Main report. Food and Agriculture Organization of the United Nations, Rome

FAO (2014) Global Land Cover SHARE - Share of year 2014 (GLCSHARE). Beta released version 1.0. http://www.glcn.org/databases/ lc_glcshare_downloads_en.jsp. Accessed August 2016

FAO-Aquastat (2017) The Food and Agriculture Organization of the United Nations - Aquastat. http://www.fao.org/nr/water/aquastat/ water use/index.stm\#db. Accessed November 2016

FAO-Aquastat (2018) Produced and treated municipal wastewater. Available at: http://www.fao.org/nr/water/aquastat/wastewater/ index.stm Accessed April 2018

FAOSTAT (2016) Food Agriculture Organization of the United Nations Statistics Division. http://faostat3.fao.org/download/R/RL/E. Accessed August 2016

FAOSTAT (2018a) Crop-production quantity. Available at: http://www. fao.org/faostat/en/\#data/QC. Accessed April 2018

FAOSTAT (2018b) Food Supply - Livestock and Fish Primary Equivalent. Available at: http://www.fao.org/faostat/en/\#data/CL. Accessed March 2018

Faragò M, Benini L, Sala S, Secchi M, Laurent A (2019) National inventories of land occupation and transformation flows in the world for land use impact assessment. Int J Life Cycle Assess. 1-15. https:// doi.org/10.1007/s11367-018-01581-8

Fazio S, Castellani V, Sala S, Schau EM, Secchi M, Zampori L (2018a) Supporting information to the characterisation factors of recommended EF Life Cycle Impact Assessment methods. New models and differences with ILCD. EUR 28888 EN, European Commission, Ispra

Fazio S, Biganzoli F, De Laurentiis V, Zampori L, Sala S, Diaconu E (2018b) Supporting information to the characterisation factors of recommended EF Life Cycle Impact Assessment methods. Version 2, from ILCD to EF 3.0, EUR 29600 EN, Publications Office of the European Union, Luxembourg.

Fiedler H, Cao Z, Huang J, Wang B, Deng S, Yu G (2012) PCDD/PCDF inventories 1990 vs. 2012. Organohalogen Compd 74:1521-1524

Flörke M, Kynast E, Bärlund I, Eisner S, Wimmer F, Alcamo J (2013) Domestic and industrial water uses of the past 60 years as a mirror of socio-economic development: a global simulation study. Glob Environ Chang 23:144-156

Fraser P, Krummel P, Dunse B, Steele P, Derek N, Allison C (2011) DSEWPaC research projects 2010-11. Centre for Australian Weather and Climate Research, Aspendale, Australia. 34 pp 
Fraser P, Dunse B, Krummel P, Steele L, Derek N (2013) Australian Atmospheric Measurements \& Emissions Estimates of Ozone Depleting Substances and synthetic Greenhouse Gases. Centre for Australian Weather and Climate Research, Aspendale, Australia. 42 pp

Fraser P, Dunse B, Krummel P, Steele L, Derek N (2014) Australian \& global emissions of ozone depleting substances. Centre for Australian weather and climate research, Aspendale, Australia. 29 $\mathrm{pp}$

Fraser P, Dunse B, Krummel P, Steele L, Derek N (2015) Australian \& Global Emissions of Ozone Depleting Substances. Collaboration for Australian Weather and Climate Research, Aspendale, Australia. 29 $\mathrm{pp}$

Frischknecht R, Büsser Knöpfel S (2013) Swiss eco-factors 2013 according to the ecological scarcity method. Methodological fundamentals and their application in Switzerland. Environmental studies no. 1330. Federal Office for the Environment, Bern. $254 \mathrm{pp}$

Frischknecht R, Braunschweig A, Hofstetter P, Suter P (2000) Modelling human health effects of radioactive releases in Life Cycle Impact Assessment. Environ Impact Assess 20(2):159-189

Frischknecht R, Steiner R, Jungbluth N (2009). The ecological scarcity method - eco-factors 2006. A method for impact assessment in LCA (Methode der ökologischen Knappheit-Ökofaktoren 2006-Methode für die Wirkungsabschätzung in Ökobilanzen)

GCA (Global Carbon Atlas) (2018) $\mathrm{CO}_{2}$ emissions. Available at: http:// www.globalcarbonatlas.org/en/CO2-emissions. Accessed April 2018

GCP (Global Carbon Project) (2018) Available at: http://www. globalcarbonproject.org/. Accessed April 2918

GEIA (Global Emissions InitiAtive) (2016) Emissions of atmospheric Compounds \& Compilation of Ancillary Data (ECCAD). ECCAD released version 6.6.3, MACCity Emission dataset. http://eccad. sedoo.fr/eccad_extract_interface/JSF/page_login.jsf. Accessed October 2016

Heijungs R, Guinée J, Kleijn R, Rovers V (2007) Bias in normalization: causes, consequences, detection and remedies. Int $\mathrm{J}$ Life Cycle Assess 12(4):211-216

Houghton RA, House JI, Pongratz J, van der Werf GR, DeFries RS, Hansen MC, Le Quéré C, Ramankutty N (2012) Chapter G2 carbon emissions from land use and land-cover change. Biogeosciences. https://doi.org/10.5194/bg-9-5125-2012

Huijbregts MAJ, Hellweg S, Hertwich EG (2011) Do we need a paradigm shift in life cycle impact assessment? Environ Sci Technol 45:38333834

Humbert S (2009) Geographically differentiated life-cycle impact assessment of human health. PhD Thesis. University of Berkeley. $265 \mathrm{pp}$

IEA (International Energy Agency) (2014) Key world energy statistics. Paris, France. 80 pp

IEA (International Energy Agency) (2018) Statistics and balances - IEA. Available at: https://www.iea.org/. Accessed October 2018

IPCC (2006) Guidelines for National Greenhouse Gas Inventories. http:// www.ipcc-nggip.iges.or.jp/public/2006gl/. Accessed March 2017

IPCC (2007) IPCC Climate Change Fourth Assessment Report: Climate Change 2007. http://www.ipcc.ch/ipccreports/assessments-reports. $\mathrm{htm}$. Accessed December 2016

IPCC (2013) IPCC Climate Change Fifth Assessment Report: Climate Change 2013. http://wwwipccch/ipccreports/assessmentsreportshtm. Accessed February 2017

ISO (2006) Environmental management-life cycle assessment. Requirements and guidelines. ISO 14044, Geneva, Switzerland

Keenan RJ, Reams GA, Achard F, de Freitas JV, Grainger A, Lindquist E (2015) Dynamics of global forest area: results from the FAO Global Forest Resource Assessment 2015. For Ecol Manag 352:9-20

Klimont Z, Smith SJ, Cofala J (2013) The last decade of global anthropogenic sulfur dioxide: 2000-2011 emissions. Environ Res Lett 8(1):014003
Koellner T, de Baan L, Beck T, Brandao M, Civit B, Goedkoop M, Margni M, Milà i Canals L, Müller-Wenk R, Weidema B, Wittstock B (2013) Principles for life cycle inventories of land use on a global scale. Int J Life Cycle Assess 18:1203-1215

Laurent A, Hauschild MZ (2014) Impacts of NMVOC emissions on human health in European countries for 2000-2010: use of sectorspecific substance profiles. Atmos Environ 85:247-255

Laurent A, Hauschild MZ, Golsteijn L, Simas M, Fontes J, Wood R (2013) Normalisation factors for environmental, economic and socio-economic indicators. Deliverable 5.2 of PROSUITE (FP7 project)

Leclerc A, Laurent A (2017) Framework for estimating toxic releases from the application of manure on agricultural soil: national release inventories for heavy metals in 2000-2014. Sci Total Environ 590: 452-460

Leclerc A, Laurent A (2018) Personal communication on global inventory for toxicity

Leclerc A, Sala S, Secchi M, Laurent A (2019) Building national emission inventories of toxic pollutants in Europe. Submitted to Environ Int

McIntyre BD, Herren HR, Wakhungu J, Watson RT (2009) International Assessment of Agricultural Knowledge, Science and Technology for Development (IAASTD): Global Report. Island Press, Washington DC. $590 \mathrm{pp}$

Montzka SA, McFarland M, Andersen SO, Miller BR, Fahey DW, Hall BD, Hu L, Siso C, Elkins JW (2014) Recent trends in global emissions of hydrochlorofluorocarbons and hydrofluorocarbons: reflecting on the 2007 adjustments to the Montreal Protocol. J Phys Chem A 119(19):4439-4449

Müller Schmied H, Eisner S, Franz D, Wattenbach M, Portmann FT, Flörke M, Döll P (2014) Sensitivity of simulated global-scale freshwater fluxes and storages to input data, hydrological model structure, human water use and calibration. Hydrol Earth Syst Sci 18(9): $3511-3538$

NASA (SEDAC) (2016) UN-Adjusted Population Density, version 4: Gridded Population of the World (GPW), v4 | SEDAC. http:// sedac.ciesin.columbia.edu/data/set/gpw-v4-population-densityadjusted-to-2015-unwpp-country-totals/data-download. Accessed August 2016

OECD (2016) Water withdrawal data. https://data.oecd.org/water/waterwithdrawals.htm. Accessed November 2016

OECD (2018) Wastewater treatment (\% population connected). Available at: stats.oecd.org/index.aspx?DataSetCode=water_treat. Accessed April 2018

Oita A, Malik A, Kanemoto K, Geschke A, Nishijima S, Lenzen M (2016) Substantial nitrogen pollution embedded in international trade. Nat Geosci 9(2):111-115. https://doi.org/10.1038/ngeo2635

Pfister S, Bayer P (2013) Monthly water stress: spatially and temporally explicit consumptive water footprint of global crop production. J Clean Prod 73:52-63

Pizzol M, Laurent A, Sala S, Weidema B, Verones F, Koffler C (2017) Normalisation and weighting in life cycle assessment: Quo Vadis? Int J Life Cycle Assess 22(6):853-866

Posch M, Seppälä J, Hettelingh JP, Johansson M, Margni M, Jolliet O (2008) The role of atmospheric dispersion models and ecosystem sensitivity in the determination of characterisation factors for acidifying and eutrophying emissions in LCIA. Int J Life Cycle Assess 13:477-486

Prado V, Wender BA, Seager TP (2017) Interpretation of comparative LCAs: external normalization and a method of mutual differences. Int J Life Cycle Assess 22(12):2018-2029

RADD (2016) European Commission's Radioactive Discharges Database. http://europa.eu/radd/. Accessed April 2016

Sala S, Benini L, Mancini L, Ponsioen T, Laurent A, Zelm R, Van R, Stam G Pant R (2014) Methodology for Building LCA-compliant National Inventories of Emissions and Resource Extraction. 
European Commission, Joint Research Centre, Institute for Environment and Sustainability. Publications Office of the European Union, Luxembourg, LU. 96 pp

Sala S, Benini L, Mancini L, Pant R (2015) Integrated assessment of environmental impact of Europe in 2010: data sources and extrapolation strategies for calculating normalisation factors. Int J Life Cycle Assess 20(11):1568-1585

Sala S, Benini L, Crenna E, Secchi M (2016) Global environmental impacts and planetary boundaries in LCA; EUR 28371 EN. JRC Tech Rep. https://doi.org/10.2788/64552

Sala S, Benini L, Castellani V, Vidal Legaz B, Pant R (2019) Environmental footprint - update of life cycle impact assessment methods. Resources, water, land and particulate matter. JRC technical report. EUR28636EN Luxembourg (Luxembourg): Publications Office of the European Union; ISBN 978-92-79-69336-6

Saouter E, Biganzoli F, Ceriani L, Versteeg D, Crenna E, Zampori L, Sala S, Pant R (2018) Environmental Footprint: update of Life Cycle Impact Assessment Methods - Ecotoxicity freshwater, human toxicity cancer, and non-cancer. EUR 29495 EN, Publications Office of the European Union, Luxembourg, ISBN 978-92-79-98182-1. https://doi.org/10.2760/178544

Scherer L, Pfister S (2015) Modelling spatially explicit impacts from phosphorus emissions in agriculture. Int J Life Cycle Assess 20(6): 785-795

Schlesinger WH, Klein EM, Vengosh A (2017) Global biogeochemical cycle of vanadium. Proc Natl Acad Sci 201715500

Shen H, Huang Y, Wang R, Zhu D, Li W, Shen G, Wang B, Zhang Y, Chen Y, Lu Y, Chen H, Li T, Sun K, Li B, Liu W, Liu J, Tao S (2013) Global atmospheric emissions of polycyclic aromatic hydrocarbons from 1960 to 2008 and future predictions. Environ Sci Technol 47(12):6415-6424

Simmonds PG, Rigby M, McCulloch A, O'Doherty S, Young D, Mühle J, Krummel PB, Steele LP, Fraser PJ, Manning AJ, Weiss RF, Salameh PK, Harth CM, Wang RHJ, Prinn RG (2016) Changing trends and emissions of hydrochlorofluorocarbons and their hydrofluorocarbon replacements. Atmos Chem Phys Discuss 17(7):4641-4655

Sleeswijk AW, van Oers LF, Guinée JB, Struijs J, Huijbregts MA (2008) Normalisation in product life cycle assessment: an LCA of the global and European economic systems in the year 2000. Sci Total Environ 390(1):227-240

Struijs J, Beusen A, van Jaarsveld H, Huijbregts MAJ (2009) Aquatic eutrophication. Chapter 6. In: Goedkoop M, Heijungs R, Huijbregts MAJ, De Schryver A, Struijs J, Van Zelm R (2009). ReCiPe 2008; a life cycle impact assessment method which comprises harmonised category indicators at the midpoint and the endpoint level. Report I: characterisation factors, first edition

Tian HZ, Zhu CY, Gao JJ, Cheng K, Hao JM, Wang K, Hua SB, Wang Y, Zhou JR (2015) Quantitative assessment of atmospheric emissions of toxic heavy metals from anthropogenic sources in China: historical trend, spatial distribution, uncertainties, and control policies. Atmos Chem Phys 15(17):10127-10147

UNDESA (United Nations Department of Economic and Social Affairs/ Population Division) (2012) World Urbanization Prospects: the 2011 revision

UNEP (United Nations Environment Programme) (2010) Environmental Effects of Ozone Depletion and Its Interactions with Climate Change: 2010 Assessment. Nairobi, Kenya

UNEP (United Nations Environment Programme) (2013) Global Mercury Assessment 2013 - Sources, Emissions, Releases and Environmental Transport. Available at: https://www.zaragoza.es/ contenidos/medioambiente/onu/942-eng.pdf

UNEP (United Nations Environment Programme) (2016) Global guidance for life cycle impact assessment indicators. Volume 1. ISBN: 978-92-807-3630-4. Available at: http://www.lifecycleinitiative.org/ life-cycle-impact-assessment-indicators-and-characterizationfactors/
UNFCCC (United Nations Convention on Climate Change) (2017) GHG data from UNFCCC. Available at: https://unfccc.int/process/ transparency-and-reporting/greenhouse-gas-data/ghg-data-unfccc/ ghg-data-from-unfccc. Accessed March 2018

UNSCEAR (United Nations Scientific Committee on the Effects of Atomic Radiation) (2010) UNSCEAR 2008 Report to the General Assembly, Annex B: sources and effects of ionizing radiation. 245 pp. New York

UNSCEAR (United Nations Scientific Committee on the Effects of Atomic Radiation) (2016) Collection of national and regional data on ionising radiation. Releases from nuclear fuel cycle reprocessing plants in airborne and liquid effluents. http://www.survey.unscear. org/doku.php. Accessed April 2016

UNSCEAR (United Nations Scientific Committee on the Effects of Atomic Radiation) (2017a) UNSCEAR 2016 Report to the General Assembly, Annex B: sources, effects and risks of ionizing radiation. 108 pp. New York

UNSCEAR (United Nations Scientific Committee on the Effects of Atomic Radiation) (2017b) UNSCEAR 2016 Report to the General Assembly, Annex A: sources, effects and risks of ionizing radiation. $118 \mathrm{pp}$. New York

USGS (United States Geological Survey) (2011a) Mineral commodity summaries 2011: U.S. Geological Survey, 198 pp. http://minerals. usgs.gov/minerals/pubs/mcs/2011/mcs2011.pdf. Accessed November 2016

USGS (United States Geological Survey) (2011b) Mineral yearbook 2011, vol I, Met Miner. http://minerals.usgs.gov/minerals/pubs/ commodity/myb/. Accessed November 2016

Van Drecht G, Bouwman AF, Knoop JM, Beusen AHW, Meinardi CR (2003) Global modelling of the fate of nitrogen from point and nonpoint sources in soils, groundwater and surface water. Global Biogeochem Cycles 17(4):26-1 -26-20

Van Drecht G, Bouwman AF, Harrison J, Knoop JM. (2009). Global nitrogen and phosphate in urban wastewater for the period 1970 to 2050. Global Biogeochem Cycles 23(4)

van Oers L (2015) CML-IA database, characterisation and normalisation factors for midpoint impact category indicators. Version 4.5, April 2015. Downloaded from http://www.cml.leiden.edu/software/datacmlia.html. Accessed December 2017

van Oers L, Guinée J (2016) The abiotic depletion potential: background, updates, and future. Resources 5(1):16

van Oers L, de Koning A, Guinee JB, Huppes G (2002) Abiotic Resource Depletion in LCA. Road and Hydraulic Engineering Institute, Ministry of Transport and Water, Amsterdam, The Netherlands

Verones F, Henderson A, Laurent A, Ridoutt B, Ugaya C, Hellweg S (2017) LCIA framework and modelling guidance chapter 2. In: Frischknecht $\mathrm{R}$, Jolliet $\mathrm{O}$ (eds) Global guidance for life cycle impact assessment indicators. United Nations Environment Programme, GRID-Arendal

Viña A, McConnell WJ, Yang H, Xu Z, Liu J (2016) Effects of conservation policy on China's forest recovery. Sci Adv 2(3):e1500965

Winijkul E, Yan F, Lu Z, Streets DG, Bond TC, Zhao Y (2015) Sizeresolved global emission inventory of primary particulate matter from energy-related combustion sources. Atmos Environ 107:137-147

WMO (World Meteorological Organization) (2014), Scientific Assessment of Ozone Depletion: 2014, Global Ozone Research and Monitoring Project Report No. 55, Geneva, Switzerland

WNA (World Nuclear Association) (2016a) World commercial reprocessing capacity, from "Processing of Used Nuclear Fuel". http://www.world-nuclear.org/information-library/nuclear-fuelcycle/fuel-recycling/processing-of-used-nuclear-fuel.aspx. Accessed November 2016

WNA (World Nuclear Association) (2016b) World uranium mining production. http://www.world-nuclear.org/info/Nuclear-Fuel-Cycle/ Mining-of-Uranium/World-Uranium-Mining-Production/. Accessed March 2016 
World Bank (2017) World bank data catalogue. Arable land. Available at https://data.worldbank.org/indicator/AG.LND.ARBL.HA.PC, accessed December 2017

Zampori L, and Pant R (2019a) Suggestions for updating the Product Environmental Footprint (PEF) method, EUR 29682 EN, Publications Office of the European Union, Luxembourg
Zampori L and Pant R (2019b) Suggestions for updating the Organisation Environmental Footprint (OEF) method, EUR 29681 EN, Publications Office of the European Union, Luxembourg

Publisher's note Springer Nature remains neutral with regard to jurisdictional claims in published maps and institutional affiliations. 